\title{
Measuring Responses of Harbour Seals to Potential Aversive Acoustic Mitigation Signals Using Controlled Exposure Behavioural Response Studies
}

Jonathan Gordon ${ }^{1}$, Clint Blight ${ }^{1}$, Ed Bryant ${ }^{2}$ \& Dave Thompson ${ }^{1}$

Address

1. Sea Mammal Research Unit, Scottish Oceans Institute, University of St Andrews, UK

2. Pathtrack Ltd, PathTrack Ltd. Unit 3 Chevin Mill, Leeds Road, Otley, West Yorkshire, LS21 1BT 
1. Some anthropogenic activities pose acute risks for marine species. For example, pile driving could damage the hearing of marine mammals while underwear explosions can also result in physical damage or mortality. Effective mitigation is required to reduce these risks, but the exclusion zones specified in regulations can extend over hundreds or thousands of meters and seals pose particular problems because they are difficult to detect at sea.

2. Aversive sound mitigation aims to exclude animals from high risk areas before dangerous activities take place by broadcasting specific acoustic signals. Field research is needed to identify signals that might be effective in eliciting short term avoidance in by marine species such as harbour seals (Phoca vitulina). A series of controlled-exposure experiments (CEE) were undertaken to measure seal movements in response to Acoustic Deterrence Devices (ADD) and predator calls, and to assess the effectiveness of candidate signals for aversive sound mitigation.

3. Seals were fitted with UHF/GPS transmitters providing continuous high-resolution tracks and real-time transmissions of their locations. A tracking/play-back vessel located seals at sea and transmitted either ADD signals or orca (Orcinus orca) calls over a range of distances while seals were foraging or moving between sites. Behaviour before, during, and after exposure were analysed to assess responses.

4. One hundred and ten CEEs were assessed as being of at least "adequate" quality. Of the 71 adequate trials with the Lofitech $A D D$, all 38 at ranges of less than $1 \mathrm{~km}$ (predicted received level $134.6 \mathrm{~dB}$ RMS re $1 \mu \mathrm{Pa}$ ) elicited a response. The maximum response range was $3123 \mathrm{~m}$ (predicted RL: $111 \mathrm{~dB}$ RMS re $1 \mu \mathrm{Pa}$ ). However, the responses observed did not always result in substantial movements away from the source, especially for seals that were travelling at the time of the exposures. More work is needed to better understand how exposure risks would be reduced in difference scenarios.

5. The mean net speed of horizontal movements for seals responding to aversive sounds ( 1.15 $\mathrm{m} \mathrm{s}^{-1}$ ) was only $7 \%$ higher than their mean travel speed.

6. Responses to broadcasts of orca calls were highly variable.

7. Our results suggest that signals similar to those generated by a Lofitech ADD could be used to reduce risks to harbour seals from pile driving and underwater explosions in coastal waters. More work will be needed to develop systems that match the requirements of industry and regulators and to explore whether these results can be generalised to offshore waters and to other phocids.

\section{KEYWORDS}

Coastal, behaviour, disturbance, tracking, mammals, engineering, renewable energy

\section{INTRODUCTION}

Sound propagates extremely well in most conditions underwater while, by contrast, the transmission of light is poor. As a consequence, many marine species use acoustics as their primary modality for both sensing their environment and for communication. Marine mammals have particularly acute hearing underwater and this enhanced acoustic sensitivity also makes them vulnerable to impacts from man-made underwater sound, particularly impulsive sounds such as 
those from pile driving (Dähne, Gilles et al. 2013), underwater explosions (Ketten, 1995, 2004; Koschinski, 2011 ) military sonar (Filadelfo et al., 2009) and, seismic airgun arrays (Gordon et al., 2003; Richardson, Greene, Malme, \& Thomson, 1995 ).

The development of offshore windfarms has led to a dramatic increase in construction activities in relatively shallow $(\sim<30 \mathrm{~m})$ coastal and offshore waters off northern Europe, often in areas that are used extensively by both grey seals (Halichoerus grypus) and harbour seals (Phoca vitulina). Most offshore wind turbines are mounted on steel monopiles which are driven into the sea bed using powerful hydraulic hammers. This process produces extremely loud impulsive sounds underwater (Bailey et al., 2010; Dahl, de Jong, \& Popper, 2015; Robinson, Lepper, \& Ablitt, 2007). A trend toward using bigger turbines, mounted on larger diameter piles which require more powerful hammers to drive them into place, results in the production of more powerful sound pulses. At very high levels, it is possible for such sounds to cause auditory damage leading to permanent hearing impairment (Hastie et al., 2015; Herschel, Stephenson, Sparling, Sams, \& Monnington, 2013; Lucke, Siebert, Lepper, \& Blanchet, 2009; Madsen, Wahlberg, Tougaard, Lucke, \& Tyack, 2006), while at lower levels, sounds can cause disturbance and behavioural disruption (Brandt, Diederichs, Betke, \& Nehls, 2011; Dähne et al., 2013; Russell et al., 2016; Tougaard, Carstensen, Teilmann, Skov, \& Rasmussen, 2009).

Hearing impairment induced by high levels of sound exposure can be measured as an elevation in an animal's hearing threshold; i.e. the quietest sounds they can detect at a certain frequency. These changes may be either temporary threshold shifts (TTS) or permanent threshold shifts (PTS). While extremely intense sounds can cause instantaneous impairment, PTS can also result from cumulative exposure to less powerful sounds over a period of time. In such cases both the sound level and the length of time an ear is exposed to it are important factors in determining TS. Typically, TTS is measured experimentally and can be used to predict the sound exposure levels at which PTS will occur. TTS has been induced in harbour seals in several experimental studies using captive animals (e.g. Kastak, Schusterman, Southall, \& Reichmuth, 1999; Kastak, Southall, Schusterman, \& Kastak, 2005; Kastelein, Gransier, Hoek, Macleod, \& Terhune, 2012).

During pile driving, intense sound pulses are emitted regularly over an extended period. For example, Hastie et al. (2015) reported pile driving episodes involving a median strike interval of 2 secs and extending over 4 to 5 hours during windfarm construction in the southern North Sea. The sound exposure that an animal will accumulate over the course of a pile driving episode depends on the sound field around the pile location (resulting from source characteristics and propagation loss) and on the animal's three-dimensional movements within this sound field. Assessing exposure risk involves modelling this process. For example, Herschell, Stephenson, Sparling, Sams, and Monnington (2013) calculated accumulated acoustic exposure for seals that were assumed to flee at a rate of $1.5 \mathrm{~m} \mathrm{~s}^{-1}$ from a range of "starting distances" from the pile at the start of pile driving . Predictions for exclusion zones necessary to avoid PTS ranged from $100 \mathrm{~m}$ for a $1.6 \mathrm{~m}$ diameter pile to $25 \mathrm{~km}$ for an $8.5 \mathrm{~m}$ diameter pile. Field data also indicate high levels of exposure for seals. Hastie et al. (2015) used location and dive depth data from tagged harbour seals to estimate sound exposure levels for these animals during construction of the Lincs Offshore windfarms off Lincolnshire. Combining these data with information on pile driving and a model for propagation loss, $50 \%$ of the tagged seals were shown to receive acoustic exposures that would have been expected to cause PTS based on the Southall et al. (2007) criteria. 
The use of explosives underwater is another activity that can cause physical injury and even death, as well as damaging hearing. Explosives are used during decommissioning of offshore structures and in activities such as harbour construction. They also result during removal of unexploded ordinance (Howard, Aker, \& Reid, 2012; Koschinski, 2011; von Benda-Beckmann, et al., 2015). Construction work associated with the development of windfarms, including installing submarine cables, has increased the rate of discovery of unexploded ordinance in some areas. In their recommendations for minimizing risk of damage to marine mammals from pile driving activities and from underwater explosions (JNCC, 2010a, 2010b) the UK Joint Nature Conservation Committee have suggested that mitigation exclusion ranges should not be less than $500 \mathrm{~m}$ for offshore pile driving and $1000 \mathrm{~m}$ for the detonation of explosives. They recommend that these should be considered as minimum values and that ranges should be determined on a case by case basis using models that include appropriate values for parameters such as source levels, propagation conditions, operational schedules, species sensitivity, and behaviour.

\section{Mitigation}

If activities that pose such threats are to be undertaken safely, it is necessary to employ effective mitigation procedures to reduce risks to individual animals. The regulatory guidelines and the modelling exercises mentioned above provide an indication of the ranges at which mitigation will be required to provide effective risk reduction. Current UK mitigation measures typically involve visual and acoustic monitoring by marine mammal observers to determine if animals are within exclusion zones before such activities are commenced. Marine mammals are difficult to sight at sea, seals especially so, and the ranges at which animals might be at risk often exceed the effective visual and/or acoustic detection range. In addition, developers need to work around the clock, through hours of darkness and in poor weather and sighting conditions. The trend for wind farms to be constructed further offshore, in more exposed locations means that detection conditions are likely to be worse. Thus, in most scenarios, marine mammal detection probability is unlikely to be high and the effectiveness of surveillance-based mitigation must therefore be poor.

Another potential mitigation method is to use an aversive sound to temporarily move animals away from locations where they might be at risk of damage. The feasibility of this approach was reviewed by Gordon et al., (2007) and it is now routinely required by many European regulators (BMU, 2014; JNCC, 2010a, 2010b, Lucke and Siemensma 2013). Powerful acoustic devices, often called acoustic deterrent devices (ADDs) or acoustic harassment devices (AHDs), which were developed in attempts to reduce pinniped depredation at fish farm sites are often used for this purpose. If regulators are to rely on aversive signals to protect marine mammals from hearing damage, then robust evidence is required to show how effectively and reliably they can exclude animals from areas of risk. An evidence base to support this has been growing for cetaceans. For example, Brandt Höschle, Diederichs, Betke, Matuschek, Witte,.et al. (2012b) and Brandt, Höschle, Deiderichs, Belke, Matuschek, et al. (2013) investigated porpoise responses to a particular type of ADD (the Lofitech Seal Scarer; Lofitech, Leknes, Norway) to assess its efficacy as an aversive sound source for mitigating pile driving risks for this species. They measured high levels of exclusion out to ranges in excess of 7km. While McGarry, Boisseau, Stephenson, and Compton (2017) have shown that all (15) minke whales (Balaenoptera acutorostrata) exposed to a Lofitech ADD at a range of $\sim 1000 \mathrm{~m}$ moved away at a high mean net swim speed (15 km h-1). 
The study reported here was motivated by the need to explore the efficacy of aversive sound mitigation with harbour seals. Effective mitigation will be achieved when animals are induced to move to a specified "safe" distance from the sound source before the risky activity is initiated. Thus, the study was designed to be able to accurately measure the movements of wild animals in scenarios as similar as possible to those likely to be encountered during offshore wind construction.

\section{METHODS}

\section{Field sites}

Field work was carried out at two locations in Scotland: a site encompassing, Loch Alsh, Kyle Rhea and the upper Sound of Sleat (used between $18^{\text {th }}$ and $29^{\text {th }}$ of June 2013) and the Moray Firth (used between $1^{\text {st }}$ and $25^{\text {th }}$ of June in 2014). Kyle Rhea (Figure 1 ) is a narrow channel between Skye and mainland Scotland that experiences strong tidal currents, in excess of $4 \mathrm{~m} \mathrm{~s}^{-1}$ (Wilson, Benjamins, \& Elliott, 2013). Over 100 harbour seals haulout within Kyle Rhea during the summer and extremely high densities of harbour seals forage in the narrowest part of the channel during the north-going flood tide (Hastie et al., 2016). In order to minimize disturbance to seals feeding in the narrows, playbacks were only carried out in Loch Alsh, to the north of Kyle Rhea and to the south in the upper Sound of Sleat, typically at times when animals made brief excursions out of the narrows. Even at these sites, tidal currents were often flowing at a significant rate while CEEs were being conducted

The Moray Firth (Figure 2) is a larger and more open body of water on Scotland's east coast. Onoufriou, Jones, Hastie, and Thompson (2016) analysed fine scale movement data for 37 harbour seals tagged in the Moray Firth (including the 13 seals which were subjects of this study in 2014). The typical pattern of behaviour for harbour seals in the Moray Firth was for them to move between haulout sites (e.g. Findhorn, Culbin Forest, Ardersier, Loch Fleet and the Dornoch Firth) and a series of preferred offshore areas believed to be foraging sites.

The two study sites were principally chosen because seals which had been tagged there for other research projects (Hastie et al., 2016; Onoufriou et al., 2016) were available to be used for this study. Ideally, studies intended to assess the efficacy of mitigation measures for pile driving at offshore wind farm sites would take place in areas with very similar characteristics to those of offshore wind farm sites. The Moray Firth is a reasonable proxy for current inshore wind farm sites, indeed wind farm developments have already taken place in its outer waters (Thompson et al., 2013). The characteristics of Kyle Rhea were, however, rather unlike those typical for an offshore wind farm site.

\section{Telemetry System}

To carry out controlled exposure behavioural response trials efficiently, field researchers need near real-time information on the location and behaviour of target animals. Because seals are difficult to observe at sea and are also effectively silent, telemetry capable of providing up to date localization information to researchers on a tracking/playback vessel at sea was required. A new telemetry system that combined the capacity to provide near real-time positioning of animals with on-tag data storage and periodic transmission to archival base stations on shore, was developed for this study utilising small solar-powered tags which incorporated Fastloc-GPS receivers. Fastloc is particularly useful for tracking animals, such as seals which dive, restricting access to satellite signals to irregular and brief surfacing periods (Bryant, 2007; Tomkiewicz, Fuller, Kie, \& Bates, 2010). Fastloc 
tags attached to the seal's head, acquired a snapshot of GPS data when the animal surfaced. These data were then processed by the tag using the Fastloc algorithm and the processed data were both stored in the tag and broadcast as soon as available when the seal was at the surface using UHF telemetry (in the $869.4-869.65 \mathrm{MHz}$ frequency band). On-tag processing took 20 seconds and if the seal was still on the surface processed data would be transmitted immediately. However, seals at sea had typically submerged on their next dive before processing was completed, in which case, the tag both broadcast the previously collected and processed GPS Fastloc information and also captured a new "snapshot" of GPS data when the animal next surfaced. The resulting time lag occasionally compromised close range tracking. Ephemeris data from GPS satellites aligned in time with the "snapshot" data capture were required to complete the processing of data received form the transmitter and provide a fix. These data were collected and stored continuously on the tracking vessel using a U-Blox LEA 6T GPS receiver.

On the tracking vessel, transmissions from any tags within range were received via a cluster of four UHF base stations, each with a directional antenna, set at 90 degrees to each other. These were mounted in the vessel's rigging at approximately $6 \mathrm{~m}$ above sea level. Each base station rebroadcast information from tags as soon as it was received. An additional UHF data receiver connected to a laptop computer at the instrument station on the tracking vessel received the data rebroadcast from the directional base station array. A program running in real time on this laptop completed the Fastloc calculation using the semi-processed data received from the tag through the base stations and stored satellite ephemeris data.

The processed seal locations and tracks together with the vessel's current position (from GPS) and its recent tracks were viewed in near real time on the vessel using Google Earth (Google LLC, Mountain View, CA, USA). As there was no access to the internet, static datasets (maps) covering the study site were preloaded and cached on the tracking laptop. KML network links were then set up to regularly trigger a copy of Google Earth to poll a webserver running on the same machine. A specially written Zend Framework PHP application, christened "LiveLocs", was deployed on that server. Whenever LiveLocs received an appropriate request it would convert the most recent seal and vessel locations into a new set of dynamic KML files, which were streamed back to the Google Earth program running on the laptop. This could then update its display to show the latest data. These plots of up-to-date information on seal locations and boat tracks allowed the field team to follow individual seals and to manoeuvre the research vessel into an appropriate location before initiating controlled exposure experiments (CEE) with tracked animals.

If signals were too weak or degraded to be processed to provide a GPS tag location, then the signal strengths from the four directional base stations could be compared graphically to provide an indication of an approximate relative bearing to the animal. This information could be used to move the tracking vessel towards the target animal until it was sufficiently close for a decodable signal to be received. Tests of the system in good weather conditions suggested that, with the directional aerial array mounted in the vessel's rigging at $\sim 6 \mathrm{~m}$, signals could be reliably decoded at ranges of up to $16 \mathrm{~km}$. The accuracy of Fastloc locations depends on the number of satellites used to calculate the fix. More than half of the fixes used here were made with data from eight satellites or more. Earlier studies (e.g. Bryant, 2007; Dujon, Lindstrom, \& Hays, 2014) have shown that over $50 \%$ of fixes made with eight satellites had a locational error of $10 \mathrm{~m}$ or less. Thus, much of the data had very good spatial resolution. 
Semi-processed Fastoc data were also stored on the tags and were downloaded to a series of data archiving UHF base stations which were placed at vantage points overlooking the haul-out sites likely to be visited by these animals. These base stations were fully autonomous, being powered by internal batteries charged by solar panels. When a tagged seal hauled out within range (line of sight) of a base station, stored data were transferred from its tag and archived in the base station. The data pointer in the tag was advanced to a new section of memory once the base station signalled that data had been successfully downloaded. Data were retrieved from the base stations periodically either by connecting them to a laptop using a USB cable or by wireless transfer through a handheld mobile wireless receiver. When within range, the tracking vessel could also interrogate a base station to download recent data on seal locations if required.

The combination of two-way communications between the tags and the archiving base stations and multiple methods for retrieving data from archiving base stations and tags resulted in a system that was flexible and adaptable. Two-way communications also allowed memory to be reallocated once data had been successfully archived in base stations and tags deployed on seals could also be reprogrammed if necessary. Furthermore, data could be retrieved from base stations through a number of different devices and the stations could be readily moved to new locations if seals changed their haulout patterns.

The full datasets eventually recovered from the base stations were more comprehensive than those available on the tracking vessel. This was because at any time only a subset of seals were within range of the tracking vessel and even for these animals, data might be lost because the UHF transmission was not received clearly or because transmissions from other seals overlapped and interfered with each other. A complete coordinated database of all the telemetry data was assembled once all the tags had detached during the annual moult.

\section{Tagging}

Twenty-three harbour seals were tagged; ten were captured at haul-out sites in Kyle Rhea, Skye in 2013 and 13 were captured at haul-out sites at Ardersier in the Moray Firth in 2014. Once captured, the seals were anesthetised with Zoletil ${ }^{\circledR}$ or Ketaset ${ }^{\circledR}$ and tags were attached to the fur at the back of the seal's neck using Loctite ${ }^{\circledR} 422$ Instant Adhesive. A series of morphometric measurements and biological samples were also taken at the time of capture (see Table 1). All procedures were carried out under Home Office Animals (Scientific Procedures) Act licence number 60/4009.

\section{Research Vessels}

The research platforms used for the CEE trials were a 44' and a 49' sailing vessels obtained from commercial charter fleets. UHF tracking and acoustic monitoring equipment were temporarily fitted to each vessel and science stations were established in their saloon areas. There were a number of advantages in using vessels of this type. They were large enough to carry the full complement of personnel required to carry out the CEE trails allowing flexible and effective round the clock operation but were also sufficiently simple to be run by the (suitably qualified) research team members. The vessels were quiet (especially under sail) and manoeuvrable, making them ideal for CEEs as well as being cost effective.

\section{Sound Sources}

Three sound sources were employed: 
1. A commercial ADD device, the Lofitech Seal Scarer (Lofiteh AS, Lenknes, Norway). This produces $14.5 \mathrm{kHz}$ acoustic pulses, each lasting $550 \mathrm{~ms}$, on an irregular time schedule, with intervals between pulses ranging from $0.6 \mathrm{~s}$ to $90 \mathrm{~s}$ and with a duty cycle of $12 \%$. Field measurements of the source level of the unit used for this study had a mean of $193 \mathrm{~dB}$ re $1 \mu \mathrm{Pa}$ at $1 \mathrm{~m}$ RMS (S.D. 1.9) (see Appendix). Brandt et al., (2012a) measured signals from the same Lofitech device at a series of ranges from $100-4000 \mathrm{~m}$, and estimated source level of $197 \mathrm{~dB}$ RMS assuming a propagation loss of $-20 \log$ (Range) $+1 \mathrm{~dB} \mathrm{~km}^{-1}$. The Lofitech ADD was powered by a $12 \mathrm{v}$ leisure battery.

2. A second commercial ADD device, an Airmar DB Plus II (provided by Mohn Aqua, Forres, UK), was available for the final week of the 2014 field season. The Airmar produces a $2.25 \mathrm{sec}$ emission consisting of $57-58$ short $(1.4 \mathrm{~ms})$ tonal pulses, each separated by $40 \mathrm{~ms}$. These emissions occur at regular intervals, approximately every 2 seconds (Lepper, Turner, Goodson, \& Black, 2004). Lepper et al. loc. cit. measured a source level of 192 $\mathrm{dB}$ re $1 \mu \mathrm{Pa}$ at $1 \mathrm{~m}$ for an Airmar dB II. Calibrated measurements of the unit used in this study estimated source levels of $195.3 \mathrm{~dB}$ re $1 \mu \mathrm{Pa}$ at $1 \mathrm{~m}$ RMS (SD 0.8) (see Appendix). The unit used for this study was a $24 \mathrm{~V}$ model while the model measured by Lepper et al. (2004) is believed to have been powered at $12 \mathrm{~V}$. This is likely to explain the higher source level measured in the current study.

3. The third sound source was a Lubell LL91262T underwater speaker (Lubell Labs Inc., Whitehall, Ohio, USA) broadcasting orca (Orcinus orca) vocalizations. The manufacturer's specification for this model claims a frequency range of $250 \mathrm{~Hz}-20 \mathrm{kHz}$. The speaker was driven by a 1000 W $12 \mathrm{~V}$ power-amplifier (Sony XM2200GTX) and signals were played from a Tascam DR40 solid state recorder. The signals came from sequences of calls from a group of approximately 15 orca known to hunt seals around Shetland, UK, kindly provided by $\mathrm{Dr}$ Volker Deecke (University of Cumbria, UK). These sequences were mixed digitally and repeated to provide a playback sequence with a high call density extending over 15 minutes. Field measurements indicated that source levels for the loudest calls ranged between 176 and $187 \mathrm{db}$ re $1 \mu \mathrm{Pa}$ RMS (see Appendix). However, these loud calls were only intermittently present in the recording.

Details of measurements of source levels for the three sound sources and measurements of propagation loss with range in the study sites are provided as an Appendix. Applying an appropriate propagation loss to source levels allowed the calculation of the predicted received levels (PRL) for animals at particular ranges from each sound source (see results section).

An animal's perception of a sound's loudness is also influenced by its auditory sensitivity at the sound's frequency. Kastelein, Wensveen, Hoek, and Terhune (2009) assessed the underwater hearing sensitivity of two harbour seals to narrow band signals by measuring $1 / 3$ octave sensitivity levels at a range of centre frequencies. Threshold levels averaged between their two subjects were $60 \mathrm{~dB}$ re $1 \mu \mathrm{Pa}$ RMS for a $1 / 3$ octave band centred at $16 \mathrm{kHz}$ (close to the frequency of a Lofitech $\mathrm{ADD}$ ) and $61.5 \mathrm{~dB}$ re $1 \mu \mathrm{Pa} \mathrm{RMS}$ for a band centred at $8 \mathrm{kHz}$ (close to the frequency of an Airmar $A D D)$. The loudest calls in the orca had highest acoustic energy at $\sim 2 \mathrm{kHz}$ for which the average threshold was $57.5 \mathrm{~dB}$ re $1 \mu \mathrm{Pa}$ RMS. These thresholds can be subtracted from PRLs to obtain approximate values for received levels above sensation level. 
The study areas are known to be locations with relatively high densities of harbour porpoise (Phocoena phocoena) and bottlenose dolphins (Tursiops truncatus). Both are European Protected Species, included in Annex IV of the Habitats Regulations and a permit under the Conservation (Natural Habitats, \&c.) Regulations 1994, was required to conduct these acoustic trials. A number of mitigation measures to minimize impacts on cetaceans were specified.

Between two and four observers searched for marine mammals from the deck of the research vessel before a sound source was activated, while another dedicated operator monitored a towed hydrophone system (provided by Vanishing Point Marine, Plymouth, UK) and a computer running PAMGuard porpoise detection and localization modules and spectrograms (Gillespie et al., 2008). A CEE was only initiated when there had been 15 minutes of monitoring without any visual or acoustic detections or if the boat had moved at least $500 \mathrm{~m}$ from the last cetacean detection. In addition, in the Moray Firth, no CEEs were conducted if any dolphin watching vessels could be sighted and no CEEs were carried out within $3 \mathrm{~km}$ of two well-known dolphin hot spots (the Souters and the Chanonry Narrows). Furthermore, no CEEs were conducted within the upper Moray Firth.

\section{Protocols for Controlled Exposure Experiments (CEEs)}

312 To initiate a CEE the vessel was positioned at an appropriate range from the test subjects using the real time telemetry tracking information to localise a target seal. Typically, distances between 500 and $1500 \mathrm{~m}$, which span the ranges of most proposed mitigation zones, were aimed for. If practicable, the vessel was manoeuvred at very low speed or under sail to minimize the risk of disturbance. The target animal's behavioural state influenced how CEEs were initiated. When animals were moving in a non-directed manner (such animals were assumed to be foraging) the vessel would be positioned as quietly as possible at the desired location. If, as was often the case, several tagged animals were being tracked at the same time, the vessel might be placed so that useful CEEs were carried out with more than one animal using a single transmission. When animals were moving in a directed manner, typically when they were travelling between haul-out sites and foraging sites, a "cut off" CEE would be attempted: the boat would be positioned directly ahead of the seal at a range of $2 \mathrm{~km}$ or more and would then wait, with engine off, for the animal to move within range.

The sound source would not be activated if there was any indication in the animal's track that it was aware of the vessel. Typically, an hour of tracking data would be available, with which to make an assessment of target animal's pre-exposure behaviour. CEEs would also be delayed or aborted if other potential sources of disturbance, such as shipping, were detected in the area.

Once the vessel was correctly positioned, the sound source was lowered to a depth of $5 \mathrm{~m}$ and turned on, usually at the start of the first new minute after the principal target seal had dived. This timing represented a good compromise between starting the exposure soon after a surface location had been obtained so that range would be known accurately and providing a degree of variation in the relative time in the dive sequence at which transmissions commenced.

During each CEE, the sound sources remained active for 15 minutes. The towed hydrophone system used for acoustic mitigation was monitored and recorded continuously during CEEs both as part of planned mitigation and to check that the sound source was operating correctly. The boat would 
remain hove-to and drifting while the source was active and for at least 15 minutes after it had been turned off.

\section{Analysis of Telemetry Data}

Two approaches were taken to analysing the telemetry data: A. characterization and measurement of behaviour and responses observed in animations of telemetry data and boat tracks; and B. statistical analysis of movement and dive parameters calculated from telemetry records.

\section{Visualization Software}

Archived telemetry data and vessel tracks were animated at a fine temporal scale using a second web application. Seal telemetry locations, vessel tracks and other associated KML datasets were accessed through a webserver running on the local machine. However, in this case, a browser rather than Google Earth was used. This incorporated a JavaScript interface which provided full VCR-like controls over the animation of the datasets loaded into an instance of the Google Earth Browser Plugin embedded in the main webpage. Cursors and measurement tools allowed ranges to be measured (see supporting information for examples).

\section{Animation Analysis}

Animations were scored independently by two of the authors (JG and DT). The analysts first agreed on a set of criteria to apply and measurements to make during the analysis. A preliminary analysis step was to determine a quality score for each individual CEE (i.e. for each seal in each CEE). This was used to assess whether a seal CEE could be considered an "adequate" trial to inform an assessment of behavioural responses and/or of changes in movement parameters. For example, if an animal was swimming away from the research vessel when a sound source was activated then it would be unlikely to show a change in heading. Whether or not a CEE elicited an observable response did not influence the assessment of "adequacy" as it was based on behaviour observed before the start of a broadcast.

Several broad categories of behaviour could be readily identified by observing animations of telemetry tracks including:

Travelling (TR) - directed movement over several minutes in a consistent direction. Usually observed as animals travelled between haulout and foraging sites.

Area restricted movement (AR) - Animals showing a lack of consistent heading resulting in individuals tending to remain in the same location. It is thought that in many cases these seals were foraging.

Avoidance (AV) - change in course away from the sound source. In the most dramatic cases, animals might reverse their swimming direction. More subtle responses included temporary course changes and diversions around a source with animals seeming to then continue towards their original destination.

Inshore movement (IN) - animals already close to land when broadcasts were initiated, on occasion, moved in very close to the shore then moved along the shoreline in shallow water.

Assessments of behaviour were made before during and after the sound source was active. Any clear course changes immediately after activation of the sound source were noted and measured. 
The bearing of the sound source relative to the animal's track at the start and end of the exposure were also recorded and changes in relative heading was noted. Ranges between target animals and the sound source were measured at the start and end of a broadcast using an on-screen measuring tool. Where possible, an assessment of a "tolerance range" was also made. This was a measure of the closest distance that an animal would come to an active sound source. This could be less than the range at which a response was first shown.

In addition, an overall assessment of whether or not a clear response could be identified was made by each analyst based on these measurements and an assessment of the animation. Once complete, the analysts' independent assessments for each CEE were compared and analysts jointly reviewed any instances where assessment and interpretation had differed in order to arrive at an agreed scoring and interpretation. Ninety-five percent of the first round of independent behavioural assessments were in agreement and apparent discrepancies were easily resolved.

\section{Statistical Analysis of Telemetry Tracks}

A set of parameters summarizing movements between surfacing locations (termed "steps") were extracted for all animals that were potential targets for CEEs. For seals at sea, these "steps" would typically represent movements during dives between two surfacing locations. Parameters calculated were step duration, distance between the two surfacing points and net speed between these locations, and (for 2014 data only) net swim speed through the water after allowing for tidal current. A simple index of deviation from a direct track " $D$ " was also calculated. For a path consisting of three locations $A, B$ and $C$, and two segments $A B$ and $B C$ the path deviation index $D=(A B+B C) / A C$

Steps for seals considered possible targets for CEEs (Table 2) were allocated to four CEE phases

Before - steps with a mid-time within 30 minutes of the start of a sound exposure

Start - the step during which the sound source was turned on,

During - steps, whose start times occurred when the source was active

After - steps, which were not scored as "during" and whose mid time was within 30 minutes of the end of a sound exposure.

Average values for each parameter for each phase of each seal CEE were calculated.

\section{RESULTS}

Sixty-four controlled sound exposures, involving one to three individual seals yielded information for 110 seal CEEs that were assessed as being of at least "adequate" quality. Numbers of exposures and seal CEEs completed for each sound type in each year are summarized in Table 2 and the locations of CEEs in 2013 and 2014 are shown in Figures 1 and 2. A table providing a summary of each of the 110 seal CEEs is provided in the supporting information. Water depths (below chart datum) at the seals' locations at the start of sound exposures, ranged from $0.3 \mathrm{~m}$ to $118 \mathrm{~m}$ (mean $25 \mathrm{~m}$ ) and distance from the high-water contour ranged from $137 \mathrm{~m}$ to $9.4 \mathrm{~km}$ (mean $1.3 \mathrm{~km}$ ). Figure 3 shows the tracks before during and after a CEE to two seals that were travelling before the sound source was activated. Figure 4 shows tracks for a seal which was engaged in area restricted movements, 
The typical response to sound exposures for animals engaged in restricted area movement at the start of a CEE was to show directed movement away from the sound source. Some 35\% (9 of 26) of CEEs to apparently foraging animals which were scored as responding during a CEE, resulted in the animal subsequently travelling to a haulout site without resuming foraging. The remaining $65 \%$ of seals returned to less directed movement and apparent feeding, often moving slowly back towards their location at the start of the sound exposure.

422

Seals close to shore when an exposure started, often moved further inshore and then swam alongshore in very shallow water.

Animals already engaged in directed movements, i.e. travelling animals, would usually show a course alteration: diverting around the sound source but then typically continuing towards their apparent initial goal, which was usually a known haul out or a foraging site. The mean value for such responsive course changes was 72 degrees away from the sound source. Estimated tolerance ranges (assessed for 2014 data only) varied between $225 \mathrm{~m}$ (PRL: $151.8 \mathrm{~dB}$ RMS re $1 \mu \mathrm{Pa}$ ) and >2000 m, with an average of $943 \mathrm{~m}$ (PRL: $135.5 \mathrm{~dB}$ RMS re $1 \mu \mathrm{Pa}$ ) and were often shorter than the animals range when the sound source was turned on and the ranges at which the first course change was observed.

\section{Analysis of Step Parameters}

Table 3 summarises data for duration, distance, speed and directivity for track steps during each of the four phases (before, at the start of, during and after) for all CEEs in the Moray Firth that had been scored by analysts as eliciting a response. These data are presented separately for seals that were travelling and those that appeared to be foraging at the start of a CEE. Figure 5 shows means of step duration, net swim speed and diversion index graphically. Generally, step durations, distances and net swim speeds increased during sound exposures while the diversion index was highly variable for foraging seals and increased slightly for travelling animals. Results from Freidman's two way analysis of variance comparing all 4 phases showed significant differences for distance and net swim speed for foraging seals and for distance and directionality for travelling animals. A comparison between before and during phases using Wilcoxon Signed Rank tests showed significant differences for distance and net swim speed for foraging animals and for all parameters for travelling animals. None of these statistical tests were significant when applied in the same way to data from CEEs that had been scored as non-responsive by analysts.

It is notable that net speed for travelling seals for the "during" phase, when they might be considered to be fleeing, was only slightly (7\%) higher than the animal's travelling speeds before sound exposure. The mean net swim speed over the during phase for CEEs identified as showing response were not significantly correlated with distance between the sound source and the subject (Pearson Correlation -0.234, sig. 0.152, $\mathrm{n}=39$ ).

\section{Analysts Assessments of Responses during Lofitech ADD CEEs}

Results from 71 "adequate" Lofitech CEEs (49 showing a response and 22 showing no response) are summarized in Figure 6 which shows range from seals to the sound source when it was activated for 
CEEs scored as either showing or not showing a clear response. All 38 CEEs at ranges of less than $998 \mathrm{~m}$ (PRL: $134.6 \mathrm{~dB}$ RMS re $1 \mu \mathrm{Pa}$ ) were scored as eliciting a response. The greatest range at which a response was observed was $3123 \mathrm{~m}$ (PRL: $111 \mathrm{~dB}$ RMS re $1 \mu \mathrm{Pa}$ ) with none of the eight CEEs at ranges greater than this being scored as eliciting a response.

A logistic regression model was developed (using IBM SPSS Statistics for Windows, Version 23, Armonk, NY, USA). The response variable was whether or not a response had been scored, while range from sound source, water depth, distance from the high water contour for the seal at the time the source was activated as well as the sex, age-class and number of previous exposures for the target animal, and the study site, were all included as potential explanatory variables. While range was a highly significant predictor of response $(p<0.0001)$, none of the other variables were retained in the model. (The value for Nagelkerke's pseudo R square was 0.544 and -2 Log likelihood of 53.2; indicating a model explaining approximately $55 \%$ of the variation in the outcome with a significantly better fit than the null model.) The best fit curve for proportion of responses against range is shown in Figure 6 . The predicted range for a $50 \%$ response probability based on the logistic model was 1523 m (PRL: $128 \mathrm{~dB}$ RMS re $1 \mu \mathrm{Pa}$ ).

Data on the net change in the distance between seals and the Lofitech source, while it was active during CEEs, are summarized in Figure 7. The mean change in distance during those CEEs for which a clear behavioural response was scored, was $+625 \mathrm{~m}$ (sd. 590, $n=46$ ) while the net change for CEEs for which no response was evident, was $-36 \mathrm{~m}$ (sd. 704, n=21). The negative value indicates that the animal moved closer to the sound source during the CEE. This difference in change in range was statistically significant (Mann-Whitney U Test, sig =.001). All targeted animals within $\sim 1000 \mathrm{~m}$ (PRL: $134.6 \mathrm{~dB}$ RMS re $1 \mu \mathrm{Pa}$ ) moved away, but in a few cases the net movement away over the course of a CEE was only in the order of tens of metres. Figure 7 includes individuals that were travelling towards the sound source before the start of the CEE. These instances are difficult to interpret as the likely location of the animals without the intervention of the CEE cannot be reliably predicted. Figure 7 also includes CEEs carried out in Kyle Rhea where the constrained geography and the fact that both animals and research vessel were often drifting in strong currents complicated interpretation.

In Figure 8 the net changes in range for 22 CEEs in the Moray Firth for which animals were not travelling at the start of the CEE are plotted. In this dataset all trials where subjects were within $854 \mathrm{~m}$ of the sound source at the start of the CEE increased their range from the sound source by at least $463 \mathrm{~m}$ over the course of the 15 minute sound exposure.

Analyst Assessments of Responses during orca vocalisation CEEs Figure 9 summarises information on ranges and responses for 26 CEEs using orca vocalizations. A plot of the proportion of responses against mean range for samples of six sequential CEEs ranked by range is also shown. No clear relationship between probability of response and range is evident. Although responses were scored at ranges as great as $4592 \mathrm{~m}$, at which the predicted received level for the loudest vocalizations in the broadcast orca recordings was only $109.6 \mathrm{~dB}$ re $1 \mu \mathrm{Pa}$ RMS (N.B. received level predictions at these ranges are very uncertain). The shortest range at which no response was registered was just $198 \mathrm{~m}$ with a predicted received level of $140.9 \mathrm{~dB}$ re $1 \mu \mathrm{Pa}$ RMS. 
On this occasion a seal seemed to be following the drifting playback vessel at a range of only a few hundred metres during a transmission of orca vocalisations.

A logistic regression analysis was carried out using the same suite of potential explanatory variables as for the Lofitech ADD CEEs. None of these parameters, even range at the start of the CEE, were retained as significant explanatory variables.

\section{Analysts Assessments of Responses during CEEs with an Airmar ADD}

503 The results of nine CEEs that were carried out using the Airmar ADD are summarized in Figure 10. The closest range for a non-response CEE was $653 \mathrm{~m}$ (PRL: $138.1 \mathrm{~dB}$ re $1 \mu \mathrm{Pa} R M \mathrm{RS}$ ) and the greatest range at which a response to a CEE was observed was $1037 \mathrm{~m}$ (PRL: $133.6 \mathrm{~dB}$ re $1 \mu \mathrm{Pa}$ RMS).

\section{DISCUSSION}

This study presents new information on responses of wild and unrestrained harbour seals to broadcasts from three potentially aversive sound sources: two type of acoustic deterrent device and the calls of orca, the main natural predator of harbour seals. Findings are relevant to the development of effective aversive sound mitigation to reduce risks to harbour seals from certain anthropogenic activities. They also provide new insights into how seals respond to and may be disturbed by certain anthropogenic sounds, and to predator avoidance behaviour in the real world.

Seals avoided all three sound sources. The clearest results were seen with the Lofitech ADD and for this device there were sufficient data to demonstrate a clear dose response function. The percentage of animals scored as showing a response decreased with distance from the sound source and with predicted received levels. All seals within $1 \mathrm{~km}$ of the ADD showed avoidance reactions and the dose response relationship suggests that $50 \%$ of seals reacted at ranges out to $1.5 \mathrm{~km}$.

The context in which sound exposures occur is generally expected to influence behavioural response thresholds (Ellison, Southall, Clark and Frankel, 2012). However, none of a range of contextual parameters (water depth, distance from the shore, study site and the sex, age-class and number of previous exposures for the target animals) were retained as significant predictors of response in the model. The lack of an effect from the number of times as seal had previously been a subject in a CEE suggests an absence of habituation or sensitisation effects over the course of the study.

The seal's behavioural activity state before the CEE did have an effect on the nature of their responses however. Travelling seals generally diverted around a sound source ahead of them- but usually continued towards the haul-out or a foraging sites that had appeared to be their pre-CEE destinations. By contrast, animals thought to be foraging moved quite directly away from the sound source. After the sound source was turned off most of these seals appeared to resume foraging, on some occasions seeming to gradually return towards their initial foraging site; however, some $35 \%$ showed a change from their pre-CEE behaviour and subsequently travelled to a haul out site. In these cases it would appear that the effects of disturbance was a disruption of foraging behaviour that extended over a much longer period than the exposure itself.

Evidence of behavioural responses, and difference in these between foraging and travelling animals could also be seen in the parameters describing movements and dives between surfacing locations (termed steps). Generally, animals dove for longer and moved more quickly when responding to 
537 aversive sounds. Foraging animals showed as great or greater percentage increase in these

538 parameters than did travelling animals, but with a higher variance. For foraging animals, only step

539 distance and net swim speed were significantly higher when the sound source was active compared

540 to the period before activation whereas differences were significant in travelling seals for all step

541 parameters.

542 Though significant, the 7\% increase in net horizontal swim speed for travelling seals when the source

543 was active was rather modest. Further, "escape speed" was not correlated with range from the

544 sound source, suggesting animals did not show a stronger response to louder sounds. It is likely that

545 travelling seals were already swimming at an energetically optimal swim speed and there may be

546 little possibility for sustained swimming at a higher speed (Gallon et al., 2007). This small increase

547 and rather modest net speed for seals that are assumed to be fleeing from an aversive sound is in

548 marked contrast to observations made during sound exposures of minke whales to a Lofitech ADD

549 (McGarry et al., 2017). Minke whales net swim speed was substantially higher ( 79\%) during sound

550 exposure periods compared to controls and demonstrated rather high mean escape speed during

551 sound exposures of $15.1 \mathrm{~km} \mathrm{~h}^{-1}\left(4.2 \mathrm{~m} \mathrm{~s}^{-1}\right)$. Minke whales demonstrate higher swim speeds than do

552 harbour seals (routine speeds of $8.3 \mathrm{~km} \mathrm{~h}^{-1}$ or $2.3 \mathrm{~m} \mathrm{~s}^{-1}$ and apparently higher sprint speeds of up to

5535.5 to $8.3 \mathrm{~m} \mathrm{~s}^{-1}$ and have been described as flight species in terms of their response to Orca attacks

554 (Ford \& Reeves, 2008). If high speed flight is their usual response to their main predator it is

555 unsurprising that they would use similar tactics in response to other perceived threats. Seals on the

556 other hand cannot outrun Orca and may not have developed a flight response or the capacity to

557 maintain high speed swimming and may depend on more evasive strategies.

558 Values for the rate at which animals will swim away from a sound source are used in models to 559 determine cumulative exposure of animals for activities, such as pile driving that continue over 560 substantial time periods. A seal swim speed of $1.5 \mathrm{~m} \mathrm{~s}^{-1}$ is often assumed in ElAs (Herschel et al., 561 2013). However, the observations made here suggest that this value may be too high and should 562 not be regarded as precautionary.

563 Case by case analysis of animations summarising the movements of tagged animals and the survey 564 vessel were a more effective means of making key measurements and assessment of controlled 565 exposure scenarios than bulk analysis. However, the fact that assessments of responses were made 566 by analysts who were aware of the experimental procedure and when the sound source was

567 activate, could give rise to methodological concerns. Several considerations may allay these fears.

568 The two analysts made assessments independently, there was a high (95\%) level of agreement in

569 their initial assessments and inconsistences were easily resolved. The behavioural responses being

570 scored were made from relatively straight forward data (animal tracks) using an animation tool

571 which provided limitless opportunities to review the data as often as required to make a careful

572 assessment. Changes of range and heading were measured on screen using the animation tool, and

573 the behavioural responses being scored were quite overt, assisting objective assessment. Further,

574 statistical comparison of step parameters showed significant differences between CEE phases for

575 most parameters for those seal CEEs that were scored as showing a response but not for CEEs that

576 were scored as non-responsive. 
578 Several studies of responses of harbour seals to ADD signals have been conducted recently.

579 Kastelein et al. (2015) investigated sensitivity and responses of two captive harbour seals to

580 underwater broadcasts of recordings of two different acoustic deterrent devices, the Lofitech ADD

581 used here and an Ace Aquatech ADD. Seals spent more time with their heads above water and in

582 the case of one of the animals, hauled out, during sound exposures. They seemed to be more

583 sensitive to the Ace Aquatech device than the Lofitech and while some changes in behaviour were

584 indicated during Lofitech broadcasts, these were not statistically significant. Kastelein et al. (2017)

585 observed responses of captive harbour seals to 16 different sound types which were candidate

586 signals for a bespoke aversive mitigation device. Seals kept their heads above the water of their

587 pool or hauled out when sound levels were higher than $142 \mathrm{~dB}$. These observations were interpreted

588 as indicating an SPL threshold for avoidance of $142 \mathrm{~dB}$ and a predicted exclusion range of between

589100 and $500 \mathrm{~m}$. The relatively modest responses to a Lofitech ADD and other signals observed in

590 these studies might seem to be at odds with the results reported here. However, captive seals

591 studies in a confined pool have very limited opportunities to show avoidance movements and it is

592 difficult to use results obtained from captive, constrained animals to reliably predict behaviours in

593 un-constrained, wild animals.

594 In a study with wild harbour seals, Mikkelsen et al. (2017) broadcast signals that were similar to, but

595 less powerful than, those of the Lofitech ADD, from an underwater speaker moored in shallow water

596 (5-8 $\mathrm{m})$ within a 100 metres or so of the shore. Observers at an elevated vantage point on an

597 adjacent cliff measured ranges to surfacing seals using a theodolite before, during, and after 20

598 minute ADD broadcasts. No substantial behavioural responses were evident. In fact, more seals

599 were noted surfacing at shorter ranges during exposure periods, with animals being observed as

600 close as $10 \mathrm{~m}$ from the speaker, where received levels would be at least $142 \mathrm{~dB}$ re $1 \mu \mathrm{Pa}$. These

601 researchers had no ability to track the movements of their study animals, they could only count and

602 localize seal heads when animals surfaced. Some observations, such as those of Kastelein et al.,

603 (2015) suggest that seals may spend more time at the surface with their heads above the water

604 when exposed to loud sounds which may explain the higher detection rate when the source was

605 active. All of the animals observed were in very shallow water close to shore. Remaining close to

606 shore and in shallow water may be a strategy to counter orca predation. When CEEs were carried

607 out within several hundred metres of shore in the current study, seals were observed to move into

608 very shallow water and often to swim along the shoreline to move further away from the sound

609 source. Thus, it is likely that Mikkelsen et al. (2017) provide some insight into how seals behave in

610 very shallow inshore habitats but it may not be appropriate to extrapolate from these findings to

611 predict behaviour in deeper waters further from the shore. This emphasizes the importance of

612 carrying out CEE trials of potential mitigation devices in habitat types and topographies which are

613 similar to those in which they will be required to operate. One of the field sites for this study, the

614 Moray Firth, would seem a good study site in this respect; it has recently had an offshore wind farm

615 site developed in its outer waters and further developments are ongoing. However, most of the

616 CEEs conducted during this study were relatively close to shore (average range $1.5 \mathrm{~km}$ ). There is a

617 trend for wind farms to be developed further offshore and in deeper waters and thus a need to

618 explore the extent to which findings from this study apply further offshore. 
620 The responsiveness of seals to novel anthropogenic signals revealed here illustrates that these animals will be vulnerable to disturbance from certain anthropogenic sound sources, especially when encountered offshore. The observation that seals that were apparently foraging would move away from their foraging location indicates that acoustic disturbance may have an effect on individual energy budgets. Some $35 \%$ of foraging seals disturbed in this way ceased foraging, travelled to a haulout site and hauled out. For these the effects of disturbance on feeding would seem to extend over a time period rather longer than the sound source activation time. It would be useful to explore how this would affect medium term energy budgets and its potential biological significance. Energetic consequences of disturbance for travelling seals may be less significant, potentially limited to slightly longer travel distances and higher swim speeds.

The powerful, medium to high frequency, tonal sound characteristics of the ADD signals are qualitatively similar to military sonar pulses. There have been substantial programs of research using behavioural response studies to establish cetacean dose response relationships to military sonar (e.g. reviewed by Harris et al., 2018), but no dedicated fieldwork to derive the same information for wild phocids. In the absence of these, the results of this study provide some indication of the responses that might be expected and also research approaches that might prove effective.

\section{7}

\section{Predator Avoidance}

638 The variability in responses of seals to playbacks of orca calls seen in this study was striking. Some responses at considerable range and at very low predicted received levels were observed, but there were also instances where no apparent responses were observed at much closer ranges. , including one instance of a seal following the drifting research vessel at close range during an orca CEE. Range was not a significant predictor of response probability.

Orcas are the major predators of seals in the study area and strong responses to their calls might be expected. Lack of a consistent response seems surprising but may reflect a sophisticated, adaptable but incompletely understood anti-predator behaviour, with different strategies (flight or surveillance) being favoured in different contexts. Deecke, Slater and Ford (2002) showed that harbour seals close to haul-out locations were less likely to avoid playbacks of calls of fish-eating than of mammal-eating killer whales, providing an indication of a nuanced antipredator behaviour in this species. In addition, differing responses observed here could reflect differing experiences of predation between individual seals. The risk-disturbance hypothesis proposes that animals may perceive certain anthropogenic sounds as a threat and respond in ways that reflect their perceived predation risk and anti-predator strategies (Frid \& Dill, 2002; Harris et al., 2018). The results of this study provide only limited support for this. Seals showed avoidance of both orca calls and tonal anthropogenic signals but there were indications that response to the former were more complex.

656 A primary motivation for this work was to investigate the feasibility of using aversive sound sources to exclude seals from locations where they could be at risk of injury or damage. Three signal types were assessed for potential use as aversive sound mitigation signals. Because research with the Lofitech has previously demonstrated strong avoidance at substantial ranges by harbour porpoises 
responsiveness by minke whales (McGarry et al., 2017), this device, or similar signals, might be considered the "default" option as a mitigation sound source. Our findings suggest that these signals are also effective at predictably eliciting a behavioural response from harbour seals at significant ranges. With all seals at ranges out to $\sim 1 \mathrm{~km}$ showing a response and $50 \%$ of seals predicted to respond at $\sim 1500 \mathrm{~m}$. In addition, there were no indications that seals became less responsive to the Lofitech ADD after repeated CEEs.

When aversive sounds are used for mitigation the desired outcome is the exclusion of all animals from a mitigation zone by the time that the potentially harmful activity commences. For seals in the Moray Firth that were not travelling at the start of Lofitech CEE, all animals within $854 \mathrm{~m}$ responded and increased their distance from the sound source by at least $458 \mathrm{~m}$ over the course of the 15 minute sound exposure.

Interpretation of results for travelling seals is more complicated in part because the extent of the animal's movement that would occur in the absence of any sound exposure makes the effect of any additional displacement due to the ADD on the likelihood of an animal being with a mitigation zone difficult to assess. CEEs to travelling seals were carried out by placing the sound source directly in the animal's apparent path. All animals within $\sim 1000 \mathrm{~m}$ showed a response which was normally to show a diversion around the sound source with a closest distance of approach (tolerance range) as low as $234 \mathrm{~m}$. It may be that the seals of greatest concern should be animals that would, in the absence of response, have been within an exclusion zone at the end of the sound exposure. In the Moray Firth telemetry dataset, the mean net horizontal speed between satellite fixes for travelling seals was $\sim 1 \mathrm{~m} \mathrm{~s}^{-1}$. Mitigation procedures recommended by JNCC for piling and use of explosives, specify 500 and $1000 \mathrm{~m}$ exclusion ranges respectively with 30 minute monitoring periods during which, if used, a ADD should be active (JNCC 2010a; JNCC 2010b). ADDs used for mitigation in German waters are also activated for 30 minutes, (Lucke and Siemensma, 2013).

In 30 minutes, a seal travelling at $1 \mathrm{~m} \mathrm{~s}^{-1}$ will have moved $1800 \mathrm{~m}$. Thus, any travelling animals that might be within the pile driving mitigation zone at the beginning of a mitigation period, and the large majority of those within an explosives exclusion zone, would be expected to have left these zones before the end of the sound broadcast. However, animals travelling toward the sound source and at ranges between 1300 and $2300 \mathrm{~m}$ at the start of mitigation for pile driving and at ranges of 800 and $2800 \mathrm{~m}$ at the start of JNCC recommended mitigation procedures for explosives use, would be predicted to be within the relevant exclusion zones at the start of the activity. Some of these ranges are greater than the ranges at which a clear response was elicited in the trials reported here and animals at these greater ranges were rarely the "target" animals for CEEs in this study and so are under-represented. Furthermore, a seal's "experience" of ADD signals as it moved towards the sound source from these ranges would be of signals with low received levels, increasing gradually as the animal swam towards the source. It is difficult to predict from the data collected in this study how an animal would respond. It could be argued that, in the absence of any element of "surprise", it will come closer to the source, alternatively it might be supposed that animals which become aware of a feature to be avoided at a greater range would be able to avoid it with less cost in terms of additional distance travelled and may thus allow themselves a wider passing distance.

As animal responses to ADDs (and possibly also to pile driving noise) vary with their behavioural state, it will be important to know the typical behavioural patterns expected for seals at a particular 
construction site when assessing risk and planning mitigation procedures. In many cases this might require additional data to be collected during environmental assessments. Situations where seals are transiting through a construction site may pose particular challenges for mitigation (Hastie et al., 2015).

Two behavioural observations from this work are particularly pertinent for those planning to use aversive sound mitigation. The first is the propensity for seals which are near to shore to move very close inshore and then often swim along shore in very shallow waters. This may well be an effective anti-predator response but the extent to which this action would protect animals from exposure to intense sound would need to be considered in the light of local topography and propagation conditions. A second observation is that animals which were apparently foraging and displaced from a preferred area would often start to return to that "patch" soon after the end of a CEE. An implication of this is that the potentially damaging activity being mitigated should start immediately after (or even during) the mitigation broadcast.

\section{Future Work to Develop Effective Mitigation}

This study is an encouraging first step towards developing an aversive sound mitigation procedure for harbour seals. However, it has also identified several areas where further work is required.

It is evident that very high levels of exclusion cannot yet be guaranteed the ranges envisaged in guidelines such as JNCC $(2010 \mathrm{a}, \mathrm{b})$ or those suggested by cumulative exposure models (Herschel et al., 2013). This is especially in the case of travelling seals. More work is required to investigate how to achieve this. Such studies might include longer sound exposures, CEEs using qualitatively different sound types that have a stronger aversive effect, louder sound sources or the use of more than one sound source around a piling location. It will be technically difficult to create a louder sound source, and any such device would begin to pose an increasing acoustic risk in its own right. Studies are needed to investigate how animals respond to an array of sound sources in the field to and explore how multiple devices should be spaced to achieve effective mitigation.

It will also be useful to carry out some trials in a greater range of more representative offshore habitats. Thus far, trials have been restricted to inshore waters where logistics are most straightforward and sites where other research projects could provide tagged seals for this study. Piling is increasingly being carried out in offshore waters as larger wind farms are built in deeper waters. It is important to establish that the responses documented here occur in offshore waters too. It will also be important to check propagation, masking and animal responses to aversive signals in poor weather conditions and high background noise conditions.

This study was carried out with harbour seals. However, grey seals are also commonly encountered at UK, European and North American wind farm sites, especially further offshore. (Other phocid species may be of concern in other regions.) Grey seals are much larger than harbour seals and have different patterns of foraging and movement and probably have a different experience of predator risk. Responses to acoustic signals are expected to differ between species and tests should be carried out to determine the extent to which findings reported here can be generalized to other seal species.

One of the outputs of this project is the development of a telemetry system, data collection protocols and field methodology which allow data on relevant behavioural responses to be collected 
efficiently from live animals at sea. This methodology can be applied to answering most of the questions posed above and measuring responses at sea of seals (and some other marine animals) to other sources of anthropogenic or natural disturbance including military sonar and seismic surveys.

\section{ACKNOWLEDGEMENTS}

This work was funded by Scottish Government's Marine Mammal Scientific Support Research Programme MMSS/001/11 and UK's Natural Environment Research Council (NERC), and Department for Environment Food and Rural Affairs (NE/J004251/1) and NERC( National Capability SMRU1001). We are grateful for the loan of ADDs from Lofitech AS, Norway and Mohn Aqua UK, Scotland. We greatly appreciate the contributions of the hard-working field teams and boats crews in 2013 and 2014: Gary Brodin of Pathtrack Ltd, Simon Moss and the seal tagging team (SMRU), Susanne Calderan, Thomas Gordon, Ed Hewett, Meret Jucker, Russell Leaper, Lauren Medwell, Sara Niksic, Nicola Papastavrou-Brooks, Katherine Whyte. We are also grateful to the University of Aberdeen Lighthouse Field Station, Cromarty for logistical help and support.

\section{REFERENCES}

Bailey, H., Senior, B., Simmons, D., Rusin, J., Picken, G., \& Thompson, P. M. (2010). Assessing underwater noise levels during pile-driving at an offshore windfarm and its potential effects on marine mammals. Marine Pollution Bulletin, 60(6), 888-897. doi:10.1016/j.marpolbul.2010.01.003

BMU (2014). Concept for the Protection of Harbour Porpoises from Sound Exposures during the Construction of Offshore Wind Farms in the German North Sea (Sound Protection Concept), ASCOBANS Advisory Committee Meeting Information Document 3.3.3.a: 37.

Brandt, M. J., Diederichs, A., Betke, K., \& Nehls, G. (2011). Responses of harbour porpoises to pile driving at the Horns Rev II offshore wind farm in the Danish North Sea. Marine Ecology Progress Series, 421, 205-216. doi:10.3354/meps08888

Brandt, M. J., Höschle, C., Diederichs, A., Betke, K., Matuschek, R., \& Nehls, G. (2013). Seal scarers as a tool to deter harbour porpoises from offshore construction sites. Marine Ecology Progress Series, 475, 291-302.

Brandt, M. J., Höschle, C., Diederichs, A., Betke, K., Matuschek, R., Witte, S., \& Nehls, G. (2012). Effectiveness of a sealscarer in deterring harbour porpoises (Phocoena phocoena) and its application as a mitigation measure during offshore pile driving. 109pp. Retrieved from Husum, Germany:

Brandt, M. J., Höschle, C., Diederichs, A., Betke, K., Matuschek, R., Witte, S., \& Nehls, G. (2013). Far-reaching effects of a seal scarer on harbour porpoises, Phocoena phocoena. Aquatic Conservation: Marine and Freshwater Ecosystems, 23(2), 222-232 
Bryant, E. (2007). 2D location accuracy statistics for Fastloc $₫$ cores running firmware versions $2.2 \&$ 2.3. Wildtrack Telemetry Systems Ltd.

Dahl, P. H., de Jong, C. A., \& Popper, A. N. (2015). The underwater sound field from impact pile driving and its potential effects on marine life. Acoustics Today, 11(2), 18-25.

Dähne, M., A. Gilles, K. Lucke, V. Peschko, S. Adler, K. Krügel, J. Sundermeyer and U. Siebert (2013). Effects of pile-driving on harbour porpoises (Phocoena phocoena) at the first offshore wind farm in Germany. Environmental Research Letters, 8(2), 025002.

Deecke, V. B., Slater, P. J. B., \& Ford, J. K. B. (2002). Selective habituation shapes acoustic predator recognition in harbour seals. Nature, 420(6912), 171-173.

Dujon, A. M., Lindstrom, R. T., \& Hays, G. C. (2014). The accuracy of Fastloc-GPS locations and implications for animal tracking. Methods in Ecology and Evolution, 5(11), 1162-1169.

Ellison W.T., Southall B.L., Clark C.W. and Frankel A.S. (2012) A New ContextBased Approach to Assess Marine Mammal Behavioral Responses to Anthropogenic Sounds. Conservation Biology, 26(1), 21-28.

Filadelfo, R., Mintz, J., Michlovich, E., D'Amico, A., Tyack, P. L., \& Ketten, D. R. (2009). Correlating military sonar use with beaked whale mass strandings: what do the historical data show? Aquatic Mammals, 35(4), 435.

Ford, J.K.B., \& Reeves, R.R. 2007. Fight or flight: antipredator strategies of baleen whales. Mammal Review, 38(1), 50-86.

Frid A. and Dill L. (2002) Human-caused disturbance stimuli as a form of predation risk. Conservation Ecology, 6(1).

Gallon, S., Sparling, C.E., Georges, J-Y., Fedak, M.A., Biuw, M., \& Thompson, D. 2007. How fast does a seal swim? Variations in swimming behaviour under differing foraging conditions. Journal of Experimental Biology, 210,3285-3294

Gillespie, D., Gordon, J., McHugh, R., Mclaren, D., Mellinger, D. K., Redmond, P., . . .Deng, X.Y., D. (2008). PAMGUARD: semiautomated, open source software for real-time acoustic detection and localisation of cetaceans. Proceedings of the Institute of Acoustics, 30(5), 54-62.

Gordon, J., Gillespie, D., Potter, J., Frantzis, A., Simmonds, M., Swift, R., \& Thompson, D. (2003). A review of the effects of seismic surveys on marine mammals. Marine Technology Society Journal, 37(4), 16-34.

Gordon, J., Thompson, D., Gillespie, S., Lonergan, M., Calderan, S., Jaffey, B., \& Todd, V. (2007). Assessment of the potential for acoustic deterrents to mitigate the impact on marine mammals of underwater noise arising from the construction of offshore windfarms (COWRIE Ltd DETER-01-07). Retrieved from St Andrews:

Harris, C.M., L. Thomas, E.A. Falcone, J. Hildebrand, D. Houser, P.H. Kvadsheim, F.P.A. Lam, P.J. Miller, D.J. Moretti, and A.J. Read. (2018). Marine mammals and sonar: Dose-response studies, the risk-disturbance hypothesis and the role of exposure context. Journal of Applied Ecology, 55(1), 396-404.

Harris, R., Harris, C., Duck, C., \& Boyd, I. (2014). The effectiveness of a seal scarer at a wild salmon net fishery. Ices Journal of Marine Science, 71(7), 1913-1920. 
Hastie, G. D., Russell, D. J., Benjamins, S., Moss, S., Wilson, B., \& Thompson, D. (2016). Dynamic habitat corridors for marine predators; intensive use of a coastal channel by harbour seals is modulated by tidal currents. Behavioral Ecology and Sociobiology, 70(12), 2161-2174.

Hastie, G. D., Russell, D. J., McConnell, B., Moss, S., Thompson, D., \& Janik, V. M. (2015). Sound exposure in harbour seals during the installation of an offshore wind farm: predictions of auditory damage. Journal of Applied Ecology, 52(3), 631-640.

Herschel, A., Stephenson, S., Sparling, C., Sams, C., \& Monnington, J. (2013). ORJIP Project 4, Phase 1: Use of deterrent devices and improvements to standard mitigation during piling. Report submitted to the Offshore Renewables Joint Industry Programme. 97pp.

Howard, B., Aker, J., \& Reid, M. (2012). Risk management for unexploded ordinance (UXO) in the marine environment. Dalhousie Journal of Interdisciplinary Management, $8(2)$.

JNCC. (2010a). JNCC guidelines for minimising the risk of injury to marine mammals from using explosives. Retrieved from http://jncc.defra.gov.uk/pdf/JNCC_Guidelines_Explosives\%20Guidelines_Aug ust $\% 202010$.pdf

JNCC. (2010b). Statutory nature conservation agency protocol for minimising the risk of injury to marine mammals from piling noise. Retrieved from http://jncc.defra.gov.uk/pdf/JNCC_Guidelines_Piling\%20protocol_August $\% 20$ 2010.pdf

Kastak, D., Schusterman, R. J., Southall, B. L., \& Reichmuth, C. J. (1999). Underwater temporary threshold shift induced by octave-band noise in three species of pinniped. Journal of the Acoustical Society of America, 106(2), 1142-1148. doi:10.1121/1.427122

Kastak, D., Southall, B. L., Schusterman, R. J., \& Kastak, C. R. (2005). Underwater temporary threshold shift in pinnipeds: Effects of noise level and duration. Journal of the Acoustical Society of America, 118(5), 3154-3163.

Kastelein, R. A., Gransier, R., Hoek, L., Macleod, A., \& Terhune, J. M. (2012). Hearing threshold shifts and recovery in harbor seals (Phoca vitulina) after octave-band noise exposure at $4 \mathrm{kHz}$. Journal of the Acoustical Society of America, 132(4), 2745-2761. doi:10.1121/1.4747013

Kastelein, R. A., Helder-Hoek, L., Gransier, R., Terhune, J. M., Jennings, N., \& de Jong, C. A. (2015). Hearing thresholds of harbor seals (Phoca vitulina) for playbacks of seal scarer signals, and effects of the signals on behavior. Hydrobiologia, 756(1), 75-88.

Kastelein, R. A., Horvers, M., Helder-Hoek, L., Van de Voorde, S., ter Hofstede, R., $\&$ van der Meij, H. (2017). Behavioral responses of harbor seals (Phoca vitulina) to FaunaGuard Seal Module sounds at two background noise levels. Aquatic Mammals, 43(4), 347.

Ketten, D. R. (1995). Estimates of blast injury and acoustic trauma zones for marine mammals from underwater explosions. In R. A. Kastelein, J. A. Thomas, \& P. E. Nachtigall (Eds.), Sensory system of Aquatic Mammals (pp. 391 - 406). Woerden, The Netherlands: De Spil Publishers. 
Ketten, D. R. (2004) . Experimental measures of blast and acoustic trauma in marine mammals ONR Final Rep N000149711030. Woods Hole Oceanographic Institution, Woods Hole, MA, USA.12pp

Koschinski, S. (2011). Underwater noise pollution from munitions clearance and disposal, possible effects on marine vertebrates, and its mitigation. Marine Technology Society Journal, 45(6), 80-88.

Lepper, P. A., Turner, V. L. G., Goodson, A. D., \& Black, K. D. (2004). Source levels and spectra emitted by three commercial aquaculture anti-predation devices. Paper presented at the Proceedings of Seventh European Conference on Underwater Acoustics, ECUA 2004, Delft, Netherlands.

Lucke, K., Siebert, U., Lepper, P. A., \& Blanchet, M. A. (2009). Temporary shift in masked hearing thresholds in a harbor porpoise (Phocoena phocoena) after exposure to seismic airgun stimuli. Journal of the Acoustical Society of America, 125(6), 4060-4070. doi:10.1121/1.3117443

Lucke, K. and Siemensma, M., 2013. International regulations on the impact of pile driving noise on marine mammals-A literature review (No. C044/13). IMARES, Netherlands, 57pp.

Madsen, P. T., Wahlberg, M., Tougaard, J., Lucke, K., \& Tyack, P. (2006). Wind turbine underwater noise and marine mammals: implications of current knowledge and data needs. Marine Ecology-Progress Series, 309, 279-295.

McGarry, T., Boisseau, O., Stephenson, S., \& Compton, R. (2017). Understanding the Effectiveness of Acoustic Deterrent Devices (ADDs) on Minke Whale (Balaenoptera acutorostrata), a Low Frequency Cetacean. ORJIP Project 4, Phase 2. RPS Report EOR0692. Prepared on behalf of The Carbon Trust. November 2017.

Mikkelsen, L., Hermannsen, L., Beedholm, K., Madsen, P. T., \& Tougaard, J. (2017). Simulated seal scarer sounds scare porpoises, but not seals: species-specific responses to $12 \mathrm{kHz}$ deterrence sounds. Royal Society open science, 4(7), 170286.

Olesiuk, P. F., Nichol, L. M., Sowden, M. J., \& Ford, J. K. B. (2002). Effect of the sound generated by an acoustic harassment device on the relative abundance and distribution of harbor porpoises (Phocoena phocoena) in Retreat Passage, British Columbia. Marine Mammal Science, 18(4), 843-862.

Onoufriou, J., Jones, E., Hastie, G., \& Thompson, D. (2016). Investigations into the interactions between harbour seals (Phoca vitulina) and vessels in the inner Moray Firth. Scottish Marine and Freshwater Science, 7(124), 47. doi:10.7489/1805-1

Richardson, W. J., Greene, C. R. J., Malme, C. I., \& Thomson, D. H. (1995). Marine mammals and noise. San Diego, California, USA: Academic Press.

Robinson, S. P., Lepper, P. A., \& Ablitt, J. (2007). The measurement of the underwater radiated noise from marine piling including characterisation of a" soft start" period. Paper presented at the Oceans 2007-Europe.

Russell, D. J., Hastie, G. D., Thompson, D., Janik, V. M., Hammond, P. S., ScottHayward, L. A., . . . McConnell, B. J. (2016). Avoidance of wind farms by harbour seals is limited to pile driving activities. Journal of Applied Ecology, 53(6), 1642-1652. 
Southall, B. L., Bowles, A. E., Ellison, W. T., Finneran, J. J., Gentry, R. L., Greene, C. R., Jr., . . Tyack, P. L. (2007). Marine mammal noise exposure criteria: Initial scientific recommendations. Aquatic Mammals, 33(4), 411-521. Thompson, P. M., Hastie, G. D., Nedwell, J., Barham, R., Brookes, K. L., Cordes, L. S., . . . McLean, N. (2013). Framework for assessing impacts of pile-driving noise from offshore wind farm construction on a harbour seal population. Environmental Impact Assessment Review, 43, 73-85.

Tomkiewicz, S. M., Fuller, M. R., Kie, J. G., \& Bates, K. K. (2010). Global positioning system and associated technologies in animal behaviour and ecological research. Philosophical Transactions of the Royal Society B: Biological Sciences, 365(1550), 2163-2176.

Tougaard, J., Carstensen, J., Teilmann, J., Skov, H., \& Rasmussen, P. (2009). Pile driving zone of responsiveness extends beyond $20 \mathrm{~km}$ for harbor porpoises (Phocoena phocoena (L.)). Journal of the Acoustical Society of America, 126(1),11-14. doi:10.1121/1.3132523

von Benda-Beckmann, A. M., Aarts, G., Sertlek, H. Ö., Lucke, K., Verboom, W. C., Kastelein, R. A., . . Kirkwood, R. J. (2015). Assessing the Impact of Underwater Clearance of Unexploded Ordnance on Harbour Porpoises (Phocoena phocoena) in the Southern North Sea. Aquatic Mammals, 41(4), 503-523.

Wilson, B., Benjamins, S., \& Elliott, J. (2013). Using drifting passive echolocation loggers to study harbour porpoises in tidal-stream habitats. Endangered Species Research, 22(2): 125-143. 


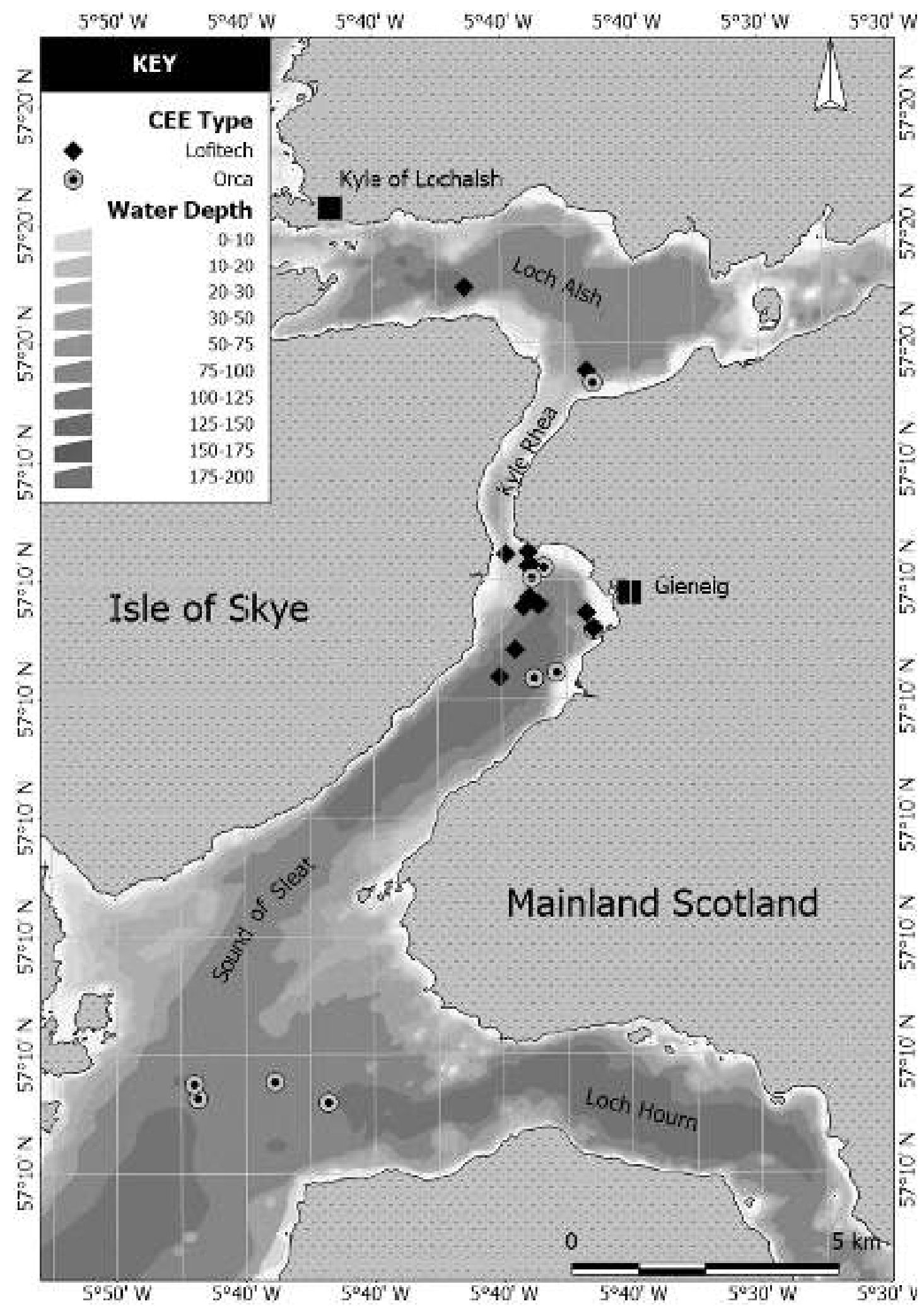

Figure 1 Kyle Rhea, Loch Alsh and Sound of Sleat study site used in 2013. Locations of both Lofitech and orca CEEs are shown 


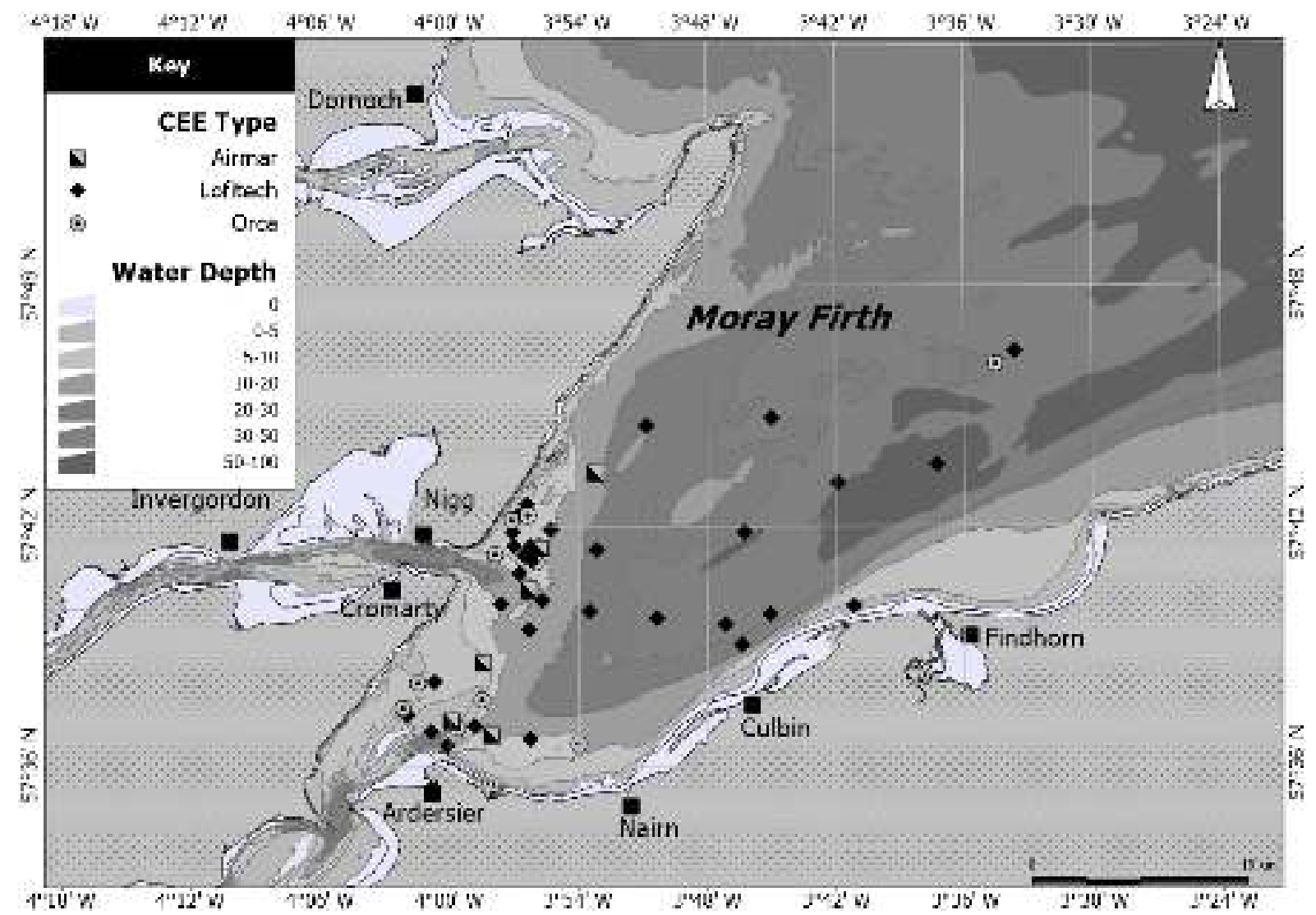

Figure 2 Moray Firth study site used in in 2014 indicating the locations of Lofitech, Orca and Airmar CEEs 


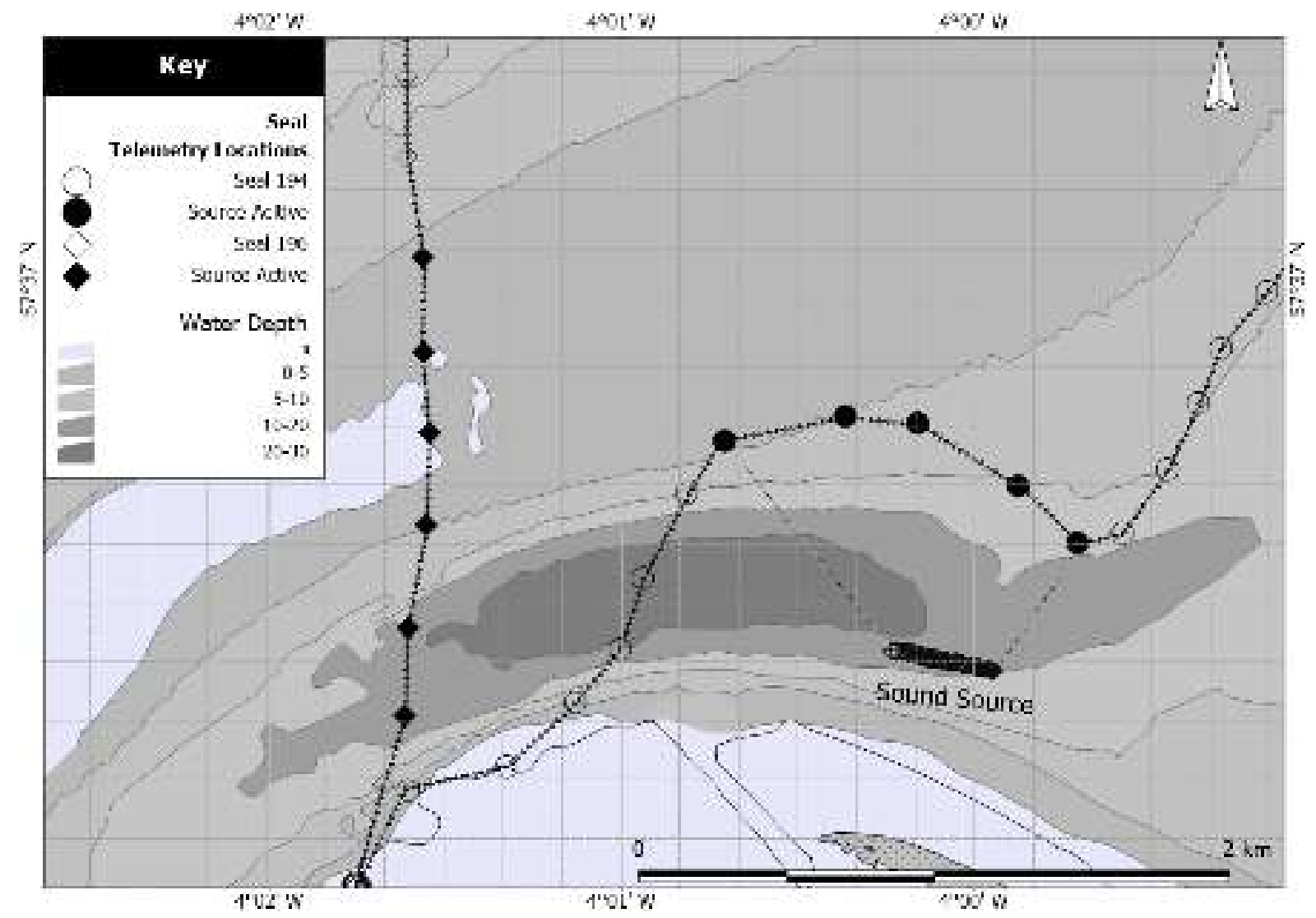

Figure 3 CCE\#5, an example of a "cut off " CEE to animals travelling towards a haulout site at Ardersier Point. During transmission the vessel drifted approximately 400m in a WNW direction. Seal 194 was the main target. Its surface locations are shown as open circles for times when the sound source was silent and as filled circles when the source was active. Before the CEE 194 was travelling SW from a foraging site and towards a haulout. The sound source, a Lofitech ADD, was activated at 08.49 UTC on 4/06/2014 when 194 was at a range of $\sim 570 \mathrm{~m}$. The seal changed course by approximately $100^{\circ}$ but then started to move back towards its original course and after the ADD transmission ceased 194 continued on into shallow water and eventually hauled out. Seal 196, (diamonds) was also travelling in a southerly direction towards a haulout. It was at range of $\sim 2,370 \mathrm{~m}$ from the sound source when activated. No response was observed, the seal moved directly into shallow water and hauled out. . A $200 \mathrm{~m}$ grid is shown 


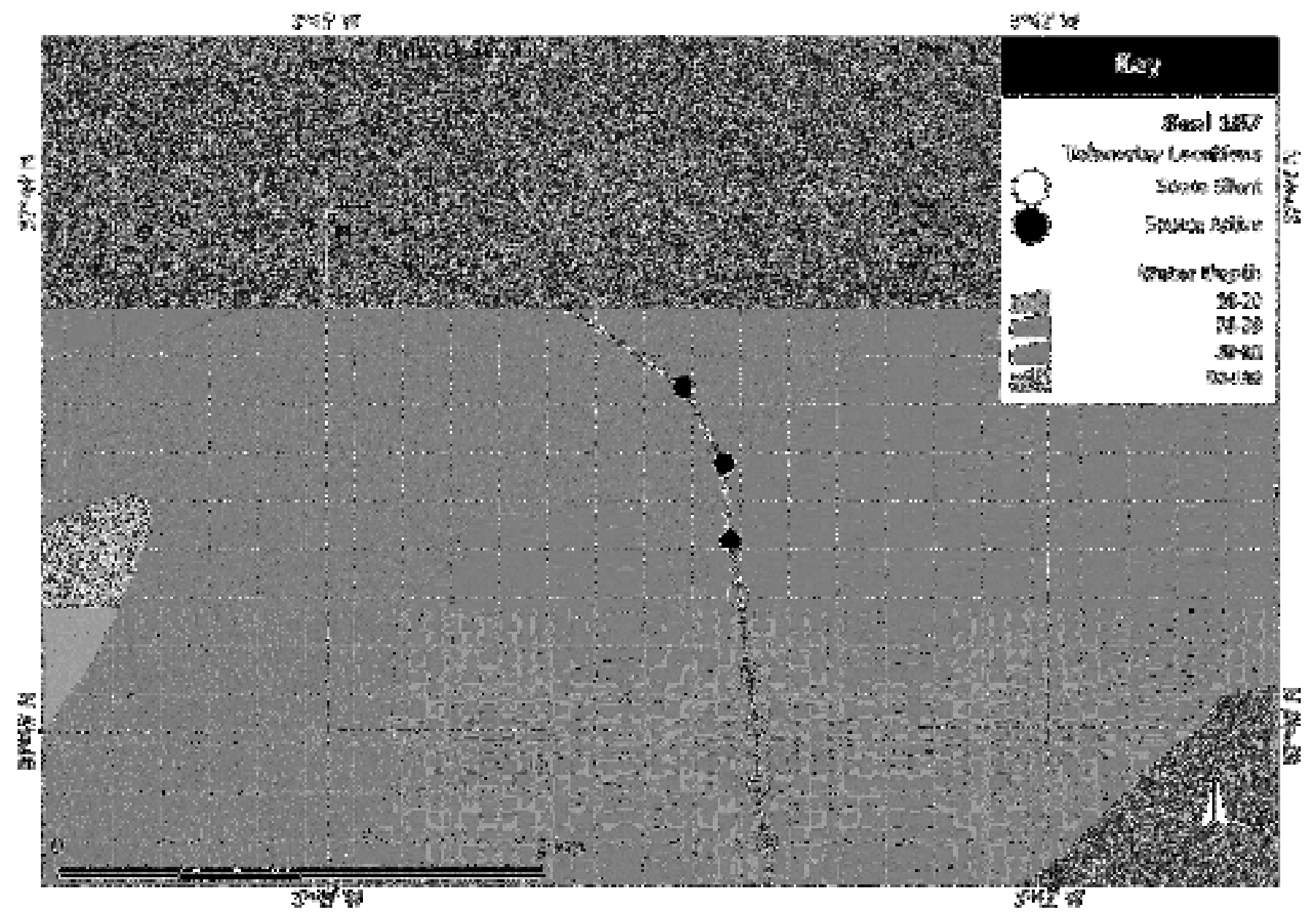

Figure 4 CEE\#31, an example of a CEE to seal, 187, which was showing area restricted movements and thought to be foraging. The boat was slowly brought into position under sail and the sound source was activated at 12:21:00 UTC on $13 / 06 / 2014$ at a range of $\sim 1030 \mathrm{~m}$. The seal moved directly away from the sound source during the CEE and subsequently continued to swim away, adjusting course slightly to take it more directly to a haulout site. The extended initial "step" might have been a long dive or a surfacing with no successful data capture. A $200 \mathrm{~m}$ grid is shown 


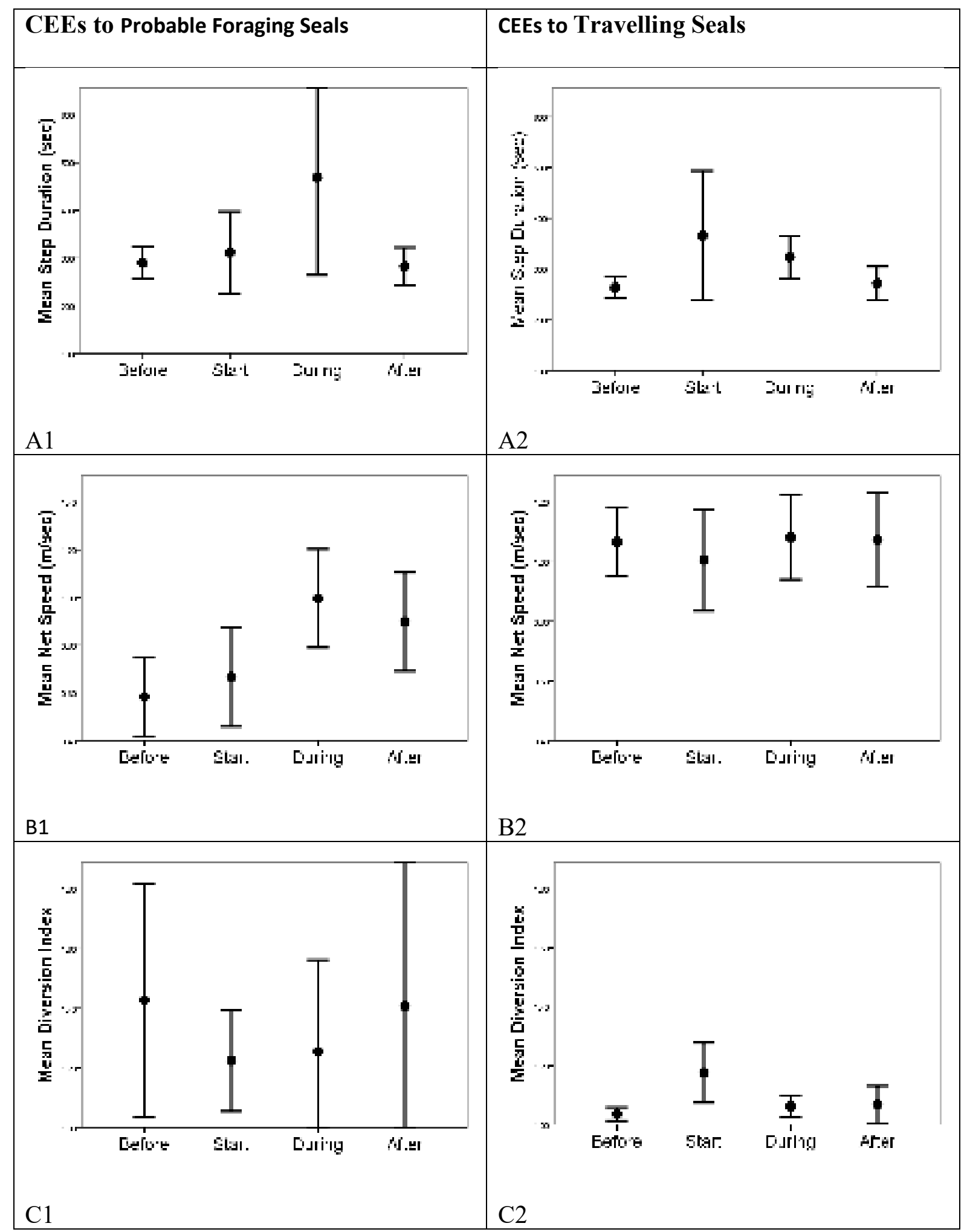

Figure 5 Plots of means and 95\% confidence intervals of average parameters for steps (intervals between telemetry fixes) before, at the start of, during and after sound exposures of all types in the Moray Firth for all CEEs which were scored by analysts as showing a response. (Steps between telemetry fixes are typically indicative of dives.) Panes A show step duration, B show net travel speed between locations after allowing for tidal current, $\mathrm{C}$ shows and index of deviation from a direct track. CEEs to seals that were moving in an area-restrictive manner, and thus thought to be foraging, (1), and those travelling immediately before the sound broadcast (2) are plotted side by side 


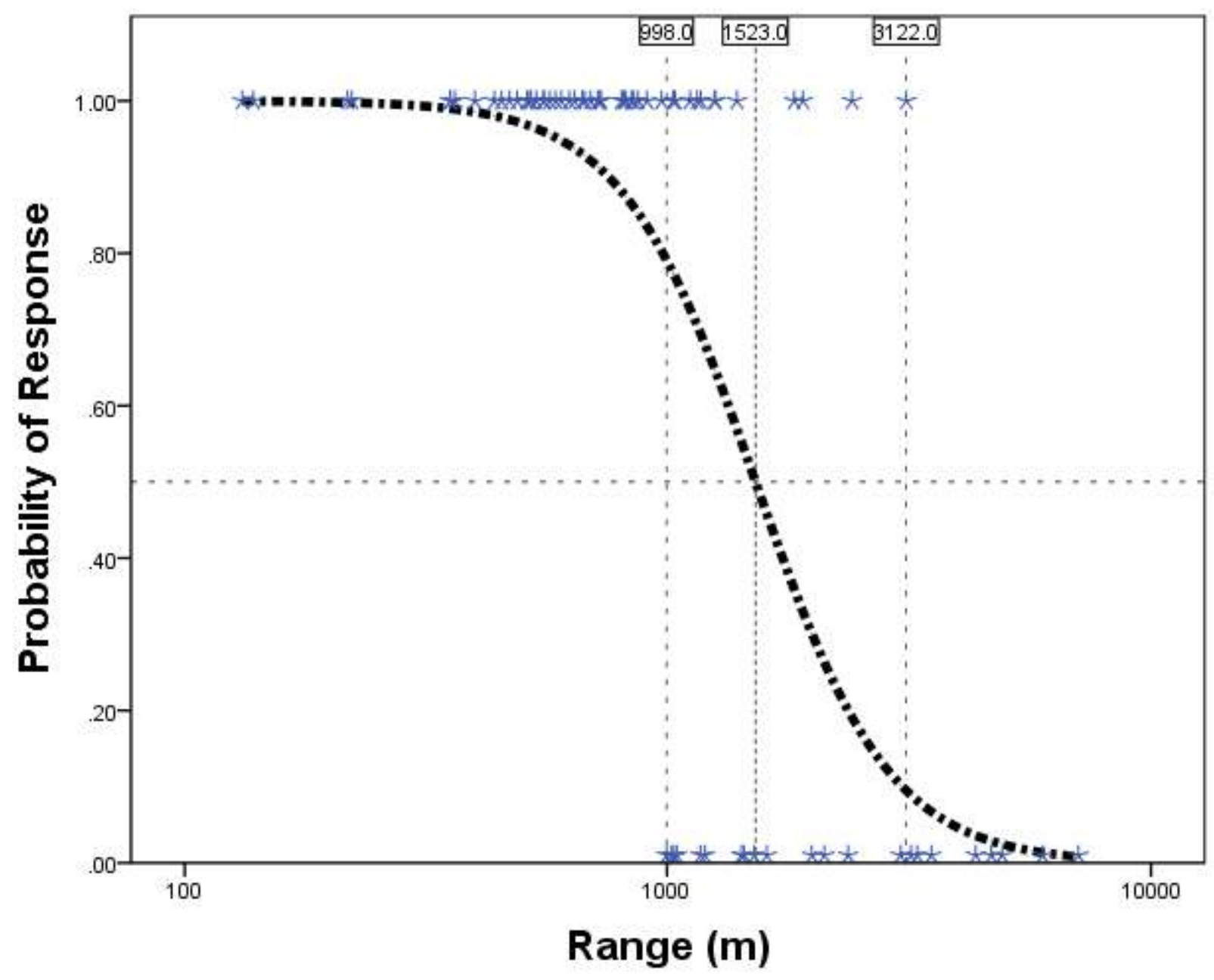

Figure 6. Summary of responses scored from analysis of telemetry animations for 71 Lofitech CEEs. CEES for which a response was observed are plotted as 1 on the y axis and those while no response are plotted at 0 . The ranges between the seal and the sound source when it was activated are shown on the $\mathrm{z}$ axis. The closest non-response and most distant response CEEs and the predicted range for $50 \%$ probability of response given by a logistic regression model are all indicated by vertical dashed lines. 


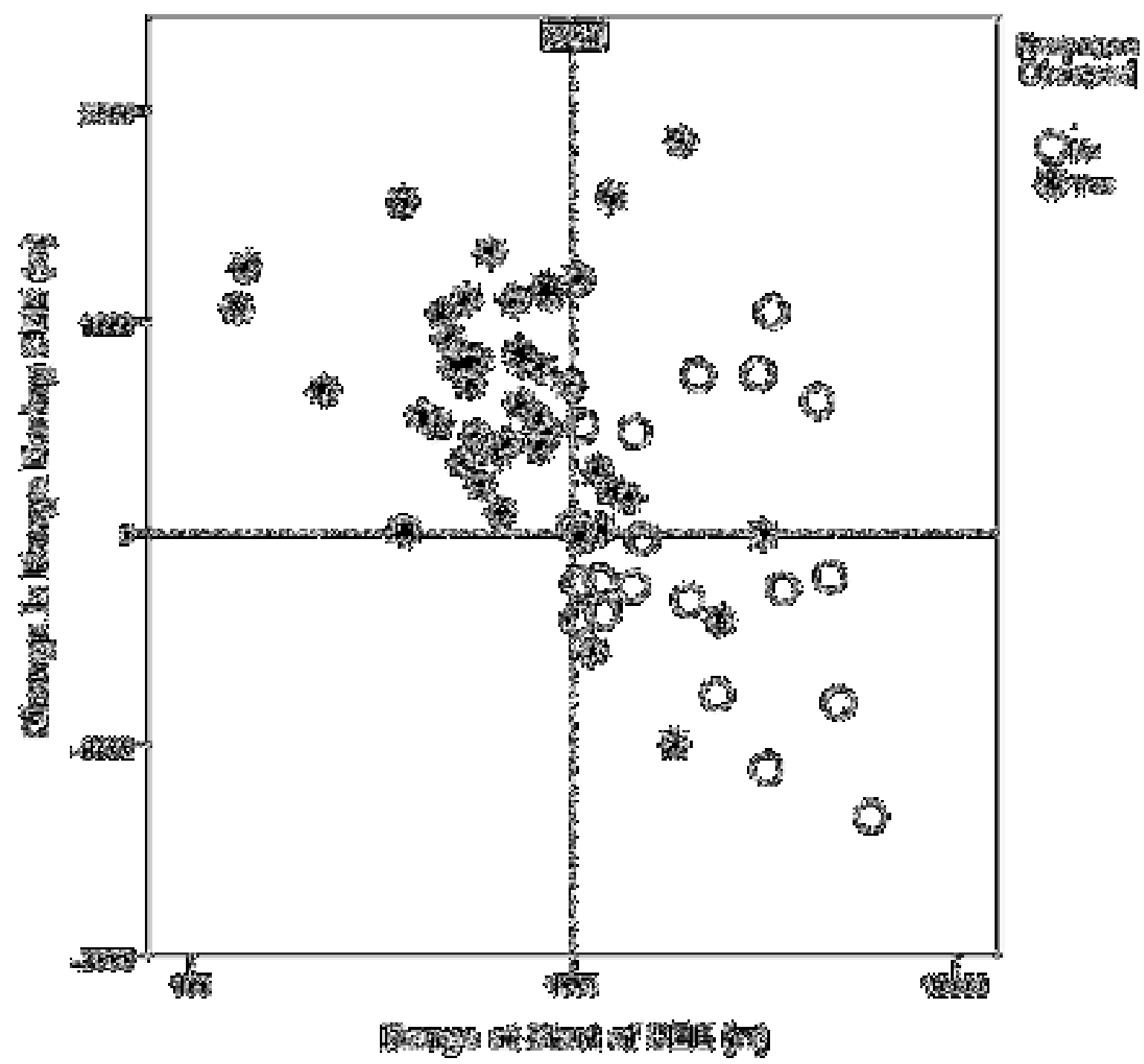

Figure 7 Net change in range over the course of 15 minute exposure to a Lofitech ADD plotted against range when the device was turned on for CEEs which resulted in a response (filled stars) and those that didn't (circles). A response was shown by all animals at a range of less than $998 \mathrm{~m}$, indicated by a dashed line 


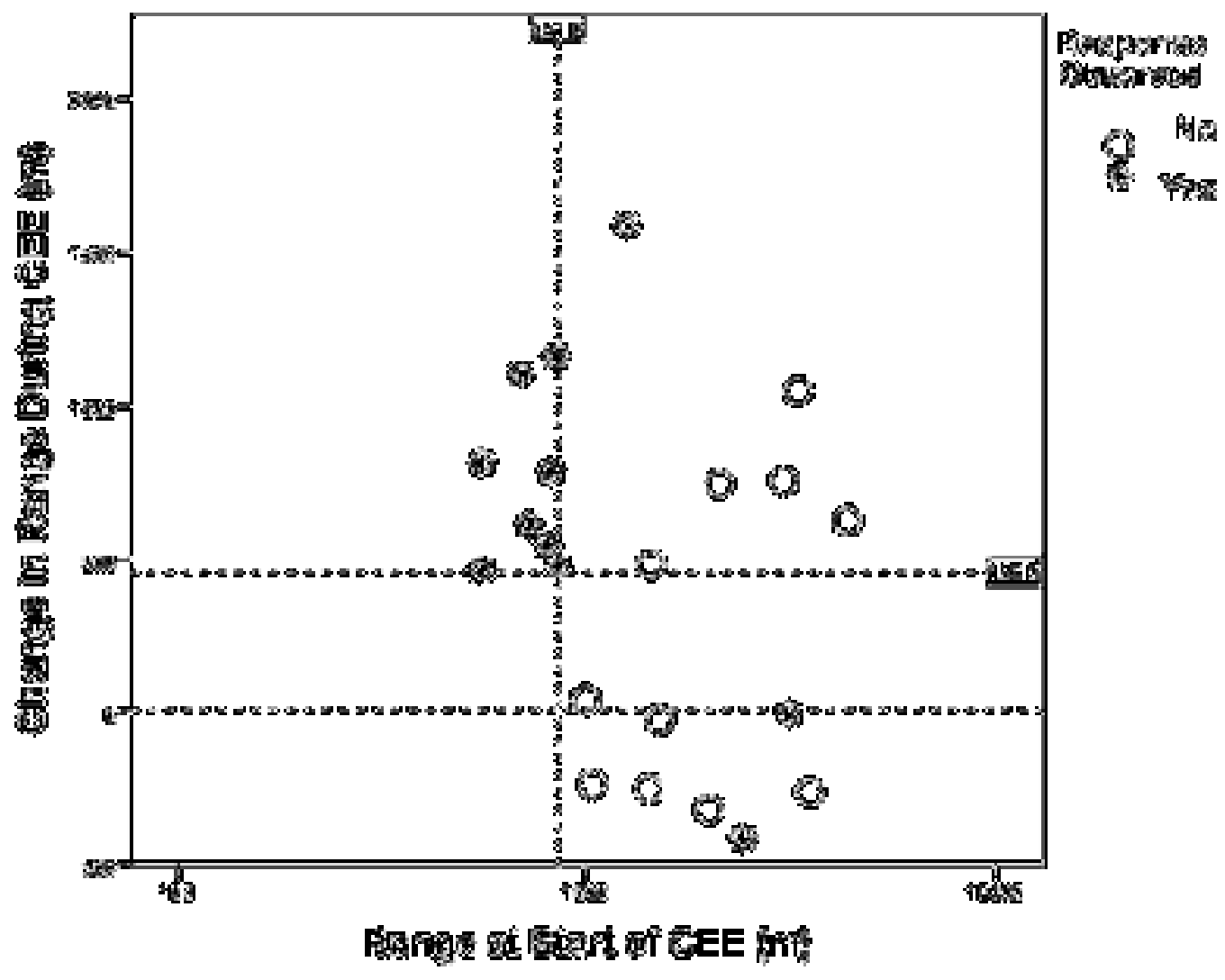

Figure 8 Net change in range to the sound source during 22 exposures to a Lofitech ADD for CEEs in the Moray Firth where initial animal behaviour was recorded as non-directed movement. All CEEs with a start range of $854 \mathrm{~m}$ or less (indicated by a vertical dashed line) showed a net displacement away from the sound source of at least $458 \mathrm{~m}$ over the course of the 15 minute sound exposure 



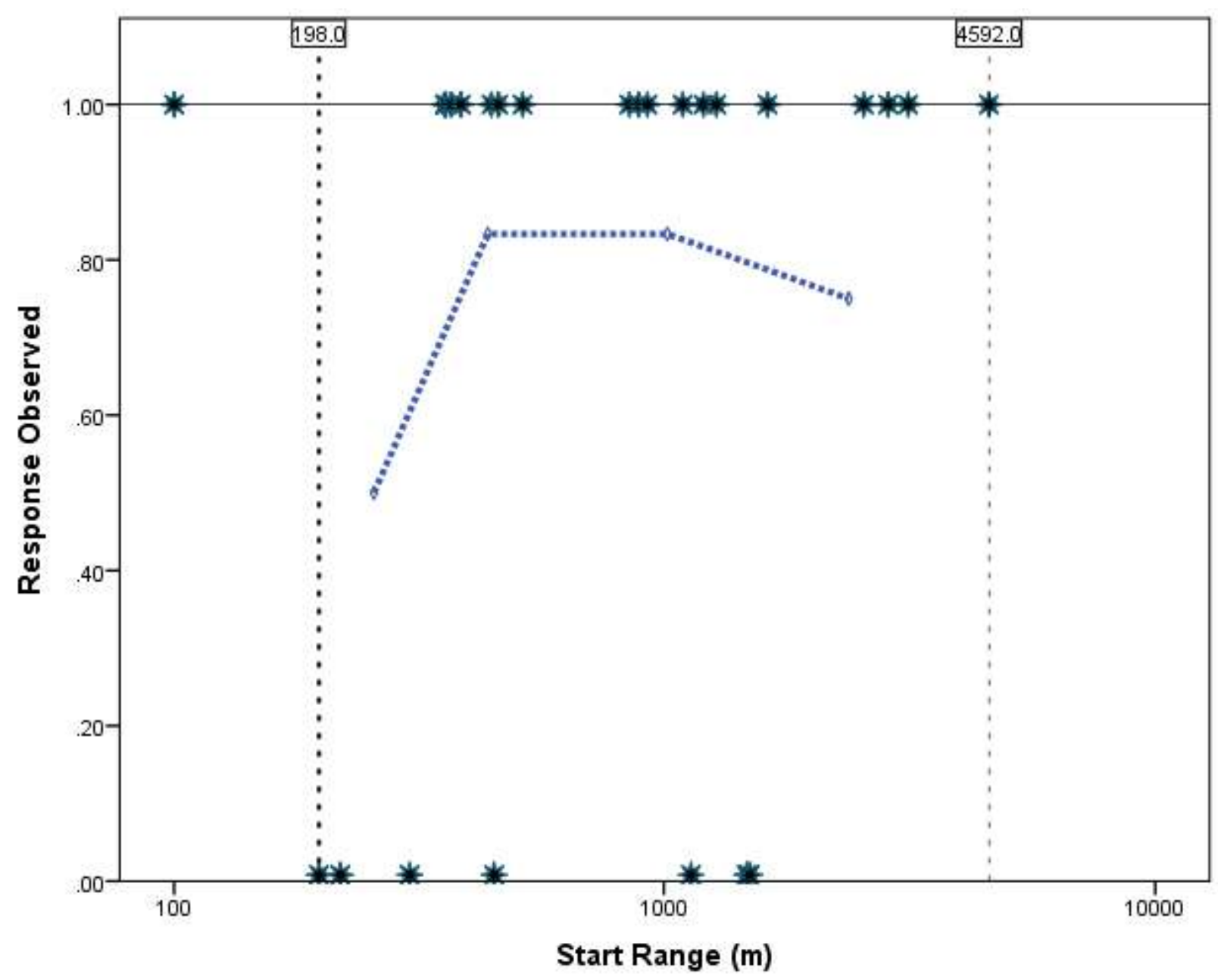

Figure 9. Ranges between the subject and the sound source when it was activated for 26 broadcasts of orca vocalisations. CEEs which were scored as showing a response ae plotted as 1 on the $y$ axis while those which were judged non-responsive at plotted at 0 . The Range for the closest non-responsive CEE and the most distant responsive CEEs are indicated by dashed vertical lines. A plot of proportion of positive responses against mean range in successive samples of 6 CEEs is indicated by diamonds joined by a dotted line. 


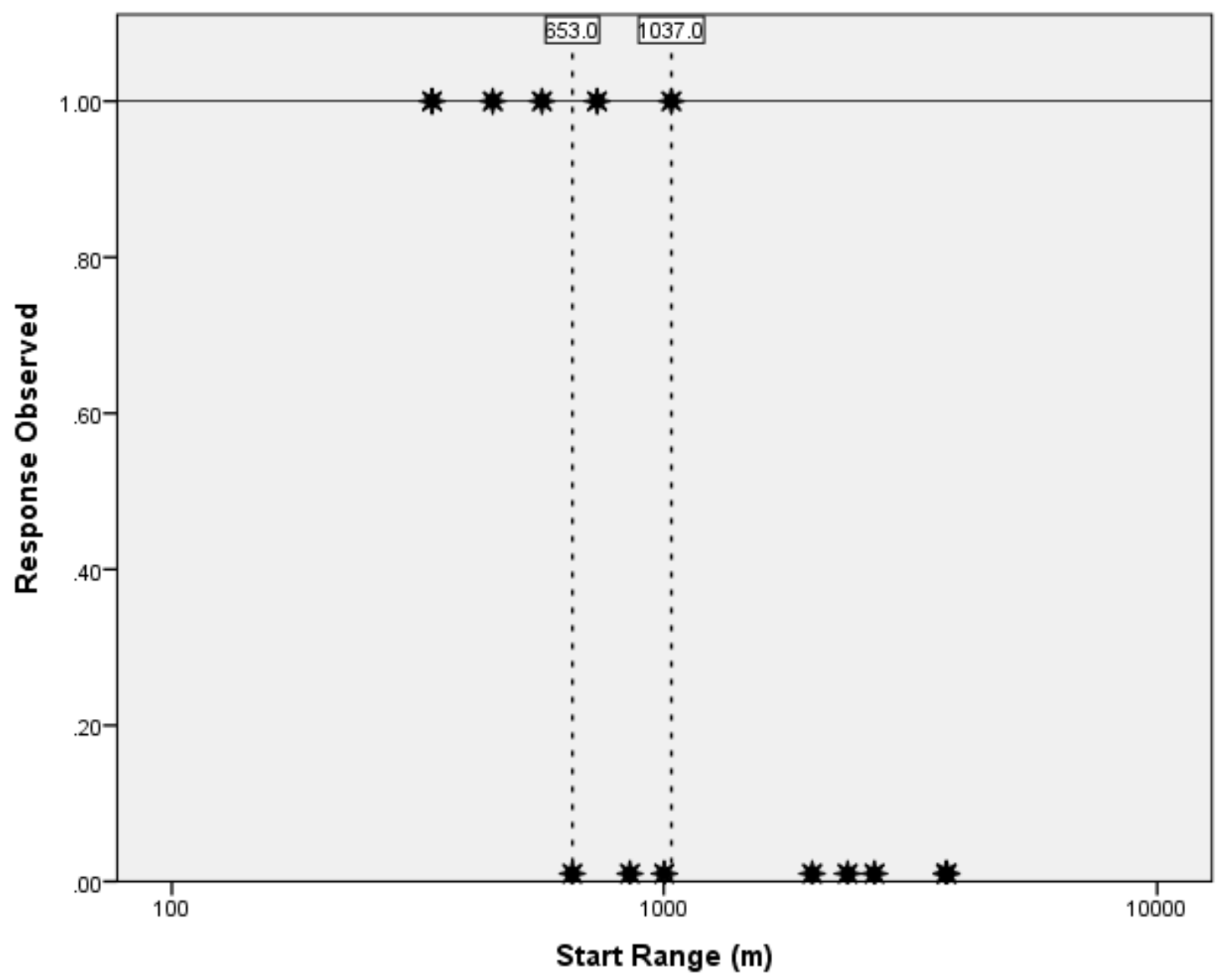

Figure 10. . Ranges between the subject and the sound source when it was activated for 9 broadcasts of an Airmar ADD. CEEs which were scored as showing a response ae plotted as 1 on the $y$ axis while those which were assessed as non-responsive at plotted at 0 . The Range for the closest non-responsive CEE and the most distant responsive CEEs are indicated by dashed vertical lines. 
A1

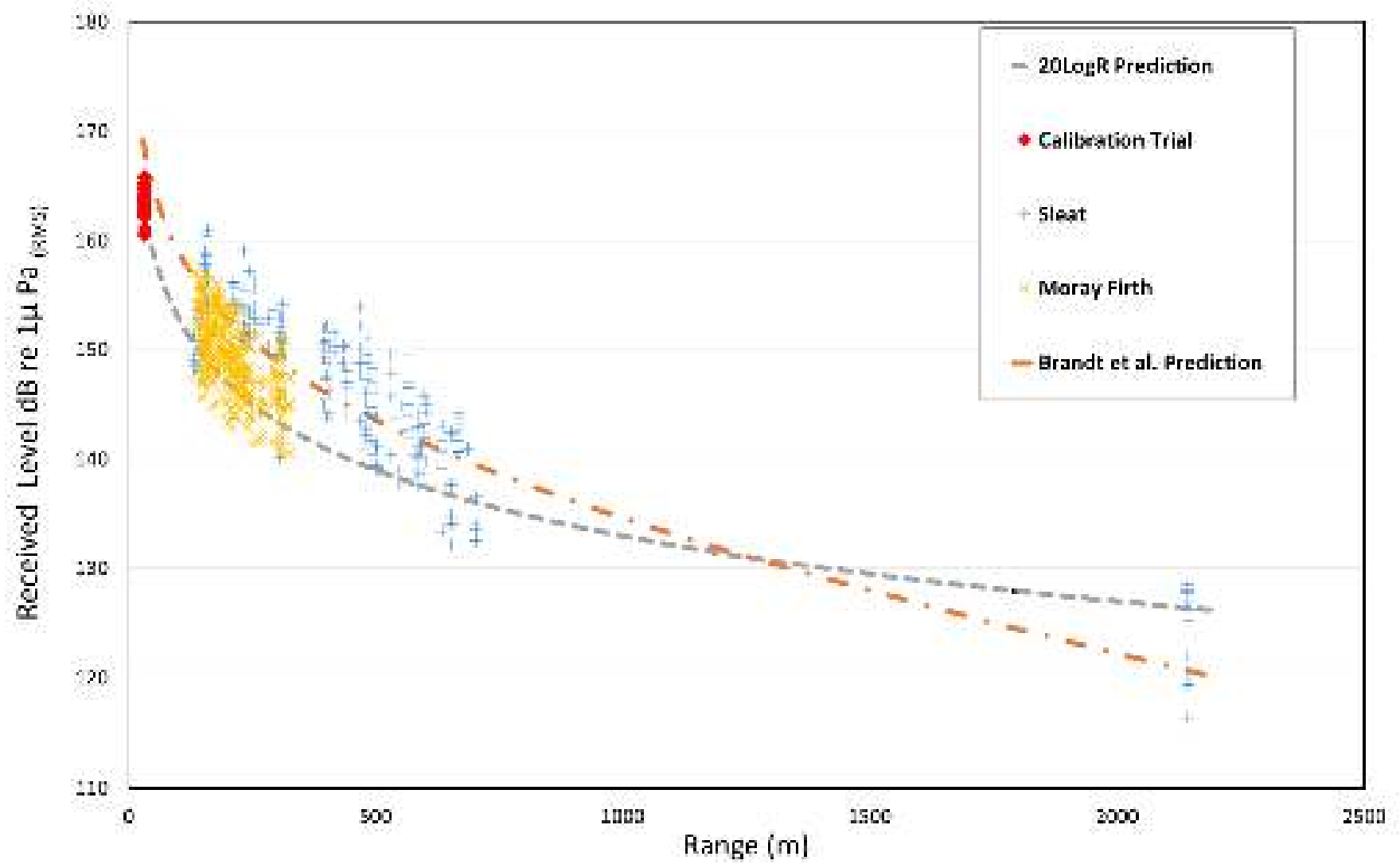

Figure A1. Plots of $\mathbf{7 1 6}$ measures of sound pressure levels against range from recordings of a Lofitech ADD in the Moray Firth and the Sound of Sleat. Lines show two predictions of received level. One using the equation for sound level with range provided by Brant et al. (2012) and the other based in the source levels measured in this study with propagation loss from spherical spreading plus frequency dependent absorption. 
Table 1 summary of seals tagged for this project. Study sites KR- Kyle Rhea, Skye; MF = Moray Firth

\begin{tabular}{|r|l|l|l|l|r|r|r|l|}
\hline $\begin{array}{l}\text { UHF } \\
\text { Tag \# }\end{array}$ & Tagging Date & $\begin{array}{l}\text { Study } \\
\text { Site }\end{array}$ & Sex & $\begin{array}{l}\text { Age } \\
\text { Class }\end{array}$ & $\begin{array}{l}\text { Mass } \\
(\mathbf{k g})\end{array}$ & $\begin{array}{l}\text { Length } \\
\text { (cm) }\end{array}$ & $\begin{array}{l}\text { Girth } \\
(\mathbf{c m})\end{array}$ & $\begin{array}{l}\text { llipper } \\
\text { Tag \# }\end{array}$ \\
\hline 55 & $17 / 05 / 2013$ & KR & F & Adult & 76.2 & 140 & 102 & 00473 \\
\hline 54 & $17 / 05 / 2013$ & KR & F & Adult & 82.6 & 138 & 102 & 00474 \\
\hline 59 & $19 / 05 / 2013$ & KR & M & Adult & 80.2 & 143 & 112 & 00475 \\
\hline 56 & $19 / 05 / 2013$ & KR & M & Adult & 81.6 & 154 & 106 & 00476 \\
\hline 62 & $21 / 05 / 2013$ & KR & M & Adult & 68.2 & 143 & 99 & 00492 \\
\hline 64 & $21 / 05 / 2013$ & KR & F & Adult & 76 & & 93 & 00480 \\
\hline 63 & $21 / 05 / 2013$ & KR & M & Adult & 87.2 & 160 & 106 & 00478 \\
\hline 57 & $21 / 05 / 2013$ & KR & M & Adult & 89.4 & 151 & 112 & 00491 \\
\hline 61 & $21 / 05 / 2013$ & KR & F & Adult & 86.4 & 140 & 108 & 00494 \\
\hline 180 & $18 / 05 / 2014$ & MF & M & Adult & 77.8 & 144 & 104 & 00503 \\
\hline 184 & $18 / 05 / 2014$ & MF & M & Adult & 81.8 & 148 & 103 & 00504 \\
\hline 183 & $20 / 05 / 2014$ & MF & M & Adult & 29.4 & 99 & 81 & 00506 \\
\hline 185 & $20 / 05 / 2014$ & MF & M & Adult & 88.8 & 151 & 109 & 00507 \\
\hline 181 & $22 / 05 / 2014$ & MF & M & Adult & 83.6 & 143 & 109 & 00508 \\
\hline 186 & $22 / 05 / 2014$ & MF & F & Adult & 90.2 & 145 & 106 & 00509 \\
\hline 187 & $22 / 05 / 2014$ & MF & M & Adult & 60.6 & 133 & 98 & 00511 \\
\hline 170 & $22 / 05 / 2014$ & MF & M & Adult & 74.8 & 149 & 103 & 00512 \\
\hline 189 & $22 / 05 / 2014$ & MF & M & Adult & 56 & 134 & 89 & 00513 \\
\hline 196 & $26 / 05 / 2014$ & MF & F & Adult & 74.2 & 134 & 100 & 00514 \\
\hline 194 & $26 / 05 / 2014$ & MF & M & Adult & 90.6 & 134 & 107 & 00515 \\
\hline 198 & $26 / 05 / 2014$ & MF & F & Adult & 82 & 135 & 100 & 00516 \\
\hline 190 & $26 / 05 / 2014$ & MF & M & Adult & 51.8 & 123 & 91 & 00517 \\
\hline & & & & & & & & \\
\hline
\end{tabular}


Table 1 Summary of numbers of sound exposures of each type and numbers of common seal CEEs (in brackets) carried out in 2013 and 2014

\begin{tabular}{|l|l|l|l|}
\hline & Total & $\begin{array}{l}\text { 2013 } \\
\text { Loch Alsh } \\
\text { and Sound of } \\
\text { Sleat }\end{array}$ & $\begin{array}{l}\text { 2014 } \\
\text { Moray Firth }\end{array}$ \\
\hline Lofitech & $\begin{array}{l}42 \\
(71)\end{array}$ & $\begin{array}{l}10 \\
(20)\end{array}$ & $\begin{array}{l}32 \\
(51)\end{array}$ \\
\hline Orca & 16 & 5 & 11 \\
& $(28)$ & $(11)$ & $(17)$ \\
\hline Airmar & 6 & & 6 \\
& $(11)$ & $(11)$ \\
\hline Total & 64 & 15 & 49 \\
& $(110)$ & $(31)$ & $(79)$ \\
\hline
\end{tabular}


Table 2. Average values for step parameters before, at start, during and after for all seal CEEs which were considered of adequate quality and scored as showing a response. Significance value for Friedmanan's two-way analysis of variance by ranks tests for comparison of mean values by CEE phase are shown. N values are the number of these comparisons tested

\begin{tabular}{|c|c|c|c|c|c|}
\hline CEE Phase & & $\begin{array}{c}\text { Step } \\
\text { Duration } \\
\text { (sec) }\end{array}$ & $\begin{array}{c}\text { Step } \\
\text { Distance } \\
(\mathrm{m})\end{array}$ & $\begin{array}{c}\begin{array}{c}\text { Net } \\
\text { Swim } \\
\text { Speed } \\
(\mathrm{m} / \mathrm{sec})\end{array} \\
\end{array}$ & $\begin{array}{c}\text { Diversion } \\
\text { Index }\end{array}$ \\
\hline \multirow[t]{3}{*}{ Before } & Mean & 290 & 164 & 0.62 & 1.43 \\
\hline & $\mathrm{N}$ & 21 & 21 & 19 & 21 \\
\hline & $\begin{array}{l}\text { Std. } \\
\text { Deviation }\end{array}$ & 73.98 & 99.20 & 0.35 & 0.86 \\
\hline \multirow[t]{3}{*}{ Start } & Mean & 311 & 179 & 0.73 & 1.22 \\
\hline & $\mathrm{N}$ & 21 & 21 & 19 & 21 \\
\hline & $\begin{array}{l}\text { Std. } \\
\text { Deviation }\end{array}$ & 189.86 & 116.98 & 0.44 & 0.38 \\
\hline \multirow[t]{3}{*}{ During } & Mean & 469 & 380 & 1.05 & 1.25 \\
\hline & $\mathrm{N}$ & 21 & 21 & 21 & 21 \\
\hline & $\begin{array}{l}\text { Std. } \\
\text { Deviation }\end{array}$ & 450.05 & 371.36 & 0.46 & 0.68 \\
\hline \multirow[t]{3}{*}{ After } & Mean & 283 & 246 & 0.96 & 1.41 \\
\hline & $\mathrm{N}$ & 20 & 20 & 19 & 20 \\
\hline & $\begin{array}{l}\text { Std. } \\
\text { Deviation }\end{array}$ & 83.37 & 154.24 & 0.42 & 1.29 \\
\hline $\begin{array}{l}\text { Freidman's } \\
\text { Two-way } \\
\text { ANOVA }\end{array}$ & Sig & . 126 & .000 & 0.01 & .746 \\
\hline $\begin{array}{l}\text { Wilcoxon } \\
\text { Signed } \\
\text { Rank Test } \\
\text { Before vs } \\
\text { During }\end{array}$ & Sig & .068 & .000 & 0.002 & .082 \\
\hline
\end{tabular}

\begin{tabular}{|c|c|c|c|c|c|}
\hline CEE Phase & & $\begin{array}{c}\text { Step } \\
\text { Duration } \\
\text { (sec) }\end{array}$ & $\begin{array}{c}\text { Step } \\
\text { Distance } \\
(\mathrm{m})\end{array}$ & $\begin{array}{c}\text { Net } \\
\text { Swim } \\
\text { Speed } \\
(\mathrm{m} / \mathrm{sec})\end{array}$ & $\begin{array}{c}\text { Diversion } \\
\text { Index }\end{array}$ \\
\hline \multirow[t]{3}{*}{ Before } & Mean & 264 & 279 & 1.07 & 1.04 \\
\hline & $\mathrm{N}$ & 23 & 23 & 22 & 23 \\
\hline & $\begin{array}{l}\text { Std. } \\
\text { Deviation }\end{array}$ & 47.83 & 88.47 & 0.27 & 0.05 \\
\hline \multirow[t]{3}{*}{ Start } & Mean & 366 & 283 & 1.00 & 1.18 \\
\hline & $\mathrm{N}$ & 25 & 25 & 24 & 25 \\
\hline & $\begin{array}{l}\text { Std. } \\
\text { Deviation }\end{array}$ & 310.41 & 125.59 & 0.42 & 0.25 \\
\hline \multirow[t]{3}{*}{ During } & Mean & 324 & 330 & 1.15 & 1.06 \\
\hline & $\mathrm{N}$ & 25 & 25 & 24 & 25 \\
\hline & $\begin{array}{l}\text { Std. } \\
\text { Deviation }\end{array}$ & 102.53 & 160.23 & 0.36 & 0.09 \\
\hline \multirow[t]{3}{*}{ After } & Mean & 272 & 278 & 1.13 & 1.07 \\
\hline & $N$ & 23 & 23 & 22 & 23 \\
\hline & $\begin{array}{l}\text { Std. } \\
\text { Deviation }\end{array}$ & 76.51 & 101.98 & 0.35 & 0.15 \\
\hline $\begin{array}{l}\text { Freidman's } \\
\text { Two-way } \\
\text { ANOVA }\end{array}$ & Sig & 0.176 & 0.018 & 0.156 & 0.022 \\
\hline $\begin{array}{l}\text { Wilcoxon } \\
\text { Signed } \\
\text { Rank Test } \\
\text { Before vs } \\
\text { During } \\
\end{array}$ & Sig & 0.033 & 0.042 & 0.024 & 0.042 \\
\hline
\end{tabular}


1 APPENDIX 1: MEASUREMENT OF SOURCE LEVELS AND

2 TRANSMISSION LOSS

\section{Source Levels}

5

Measurements of sound source levels were made using calibrated equipment in sheltered, quiet waters in Loch Ness and in Loch Oich in 2014. Sound files were captured using Reson TC4033 and TC4013 hydrophones in conjunction with a calibrated amplifier and filter unit (Reson VP200). Data were digitised with a National Instruments USB-6251 digital acquisition board at a sampling rate of $500 \mathrm{kHz}$ using PAMuard software (Gillespie et al., 2008). The $12 \mathrm{v}$ batteries used to power the sound broadcast equipment were fully charged and battery voltages was checked throughout the trials. Recordings were made at ranges between 25 and $33 \mathrm{~m}$ from the sound source. These distances were measured using both a laser range finder and a tape measure. Both sound source and recording hydrophones were deployed at a depth of $3 \mathrm{~m}$.

Acoustic measurements were made from recordings using Raven Pro v1.4 interactive sound analysis software (Cornell Bioacoustics Research Program, Cornell, USA). Recordings of ADDs were high-pass filtered at $5 \mathrm{kHz}$ while recordings of killer whale broadcasts were high-pass filtered at $1 \mathrm{kHz}$. Sections of recordings for acoustic measurement were selected by hand using a cursor tool. Loftiech emissions are a series of 0.5 second tonal pulses and to analyse these the whole pulse was selected for measurement. Airmar emissions consist of a series of short ( $1.4 \mathrm{msec}$ pulses) with a $40 \mathrm{msec}$ spacing which are emitted in blasts lasting 2.25secs. Measurement of Airmar pulses were made using both selections which included the complete blast and selections for each individual $1.4 \mathrm{msec}$ pulse within it. The killer whale signals were quite variable and complex, and measurements were made of the loudest calls selected using the cursor.

Results are summarised in Table A.1.

The average source level for 39 Lofitech pulses recorded in Loch Ness on 28/05/2014 was 193 dB re $1 \mu \mathrm{Pa} @ \mathrm{~m}$ RMS with a standard deviation of 1.9, while measurements of 52 pulses made from recordings in Loch Oich a month later (27/06/2014) gave a mean source level 192.9 dB re $1 \mu \mathrm{Pa} @ \mathrm{~m}$ RMS with a standard deviation of 3.45 .

\section{Table A.1 Means and standard deviations of measured source levels for the three signal types used in CEEs}

\begin{tabular}{|l|l|l|l|l|}
\hline $\begin{array}{l}\text { Sound } \\
\text { source }\end{array}$ & Date and location & $\begin{array}{l}\text { Number of } \\
\text { Measurements }\end{array}$ & $\begin{array}{l}\text { Mean RMS } \\
\text { dBre 1 } \boldsymbol{\mu P a @ 1 m ~}\end{array}$ & SD \\
\hline Lofitech & Loch Ness 28/05/2014 & 39 & 193.0 & 3.1 .9 \\
\hline Lofitech & $\begin{array}{l}\text { Loch Oich } \\
27 / 06 / 2014\end{array}$ & 52 & 192.9 & 3.45 \\
\hline Airmar & $\begin{array}{l}\text { Loch Oich } \\
27 / 06 / 2014\end{array}$ & 17 & 195.3 & 0.85 \\
\hline Orca & $\begin{array}{l}\text { Loch Oich } \\
27 / 06 / 2014\end{array}$ & 14 & $176-187$ & na \\
\hline
\end{tabular}


These measurements of source level for the Lofitech align reasonably well with those in (Brandt et al., 2012). They found that a model with a source level of $197 \mathrm{~dB}$ and a $20 \log$ (Range) transmission loss provided a good fit to acoustic measurements of a Lofitech made in the North Sea. The source level specified on the Lofitech manufacturer's website is "189dB"; however, the measurement units and acoustic reference are not provided. Lofitch pulses have a $0.5 \mathrm{sec}$ duration. Thus, a sound exposure level (SEL) of $189 \mathrm{~dB}$ re $1 \mu \mathrm{Pa} \mathrm{s}^{-1}$ would align well with our RMS measurements suggesting the manufacturer's source level might refer to the Lofitech ADD's SEL.

The mean source level of 17 Airmar pulses measured from recordings made in Loch Oich on $27 / 06 / 2014$ was $195.3 \mathrm{~dB}$ re $1 \mu \mathrm{Pa} @ 1 \mathrm{~m}$ RMS with as standard deviation of 0.84 while the RMS source level for 8 complete blasts was 188.2 dB re 1 $\mu$ Pa@m RMS (SD 0.047). Lepper et al (2004) measured a source level of $192 \mathrm{~dB}$ re $1 \mu \mathrm{Pa} @ 1 \mathrm{~m}$ RMS for a standard 12v Airmar. The unit measured in this study was a $24 \mathrm{v}$ model which powered by twice the voltage of that tested by Lepper et al (2004). It is likely that this explains the $3 \mathrm{~dB}$ higher source level measured here.

The killer whale recordings included a range of call types with different levels. The source levels of the loudest call types are probably of most relevance. Measurement of 14 prominent calls with recordings had source levels ranging from 176 to 187 dB re $1 \mu \mathrm{Pa@1m} \mathrm{RMS.}$

\section{Propagation Loss and Received Levels}

A self-contained recording spar-buoy was used to record sound levels at greater ranges during CEEs and to provide indications of propagation loss and the likely exposure levels for the target animals. The recording buoy consisted of two HTI 96 Min hydrophones (High Tech Inc, Long Beach, MS. USA) with deployed cable lengths of $8 \mathrm{~m}$ and $15 \mathrm{~m}$, whose output was recorded on a Tascam 40D solid state recorder sampling $96 \mathrm{kHz}$ and $24 \mathrm{bit}$. The recorder and a Royal Tec RGM3800 GPS logger were mounted in a $2 \mathrm{~m}$ plastic spar buoy constructed using PVC pipe and plumbing components. This was deployed shortly before initiating CEEs and then drifted freely until the CEE had been completed and the buoy could be recovered. The ranges between the buoy and the vessel and sound source were calculated by comparing time-referenced GPS locations collected on the vessel and at the buoy. 


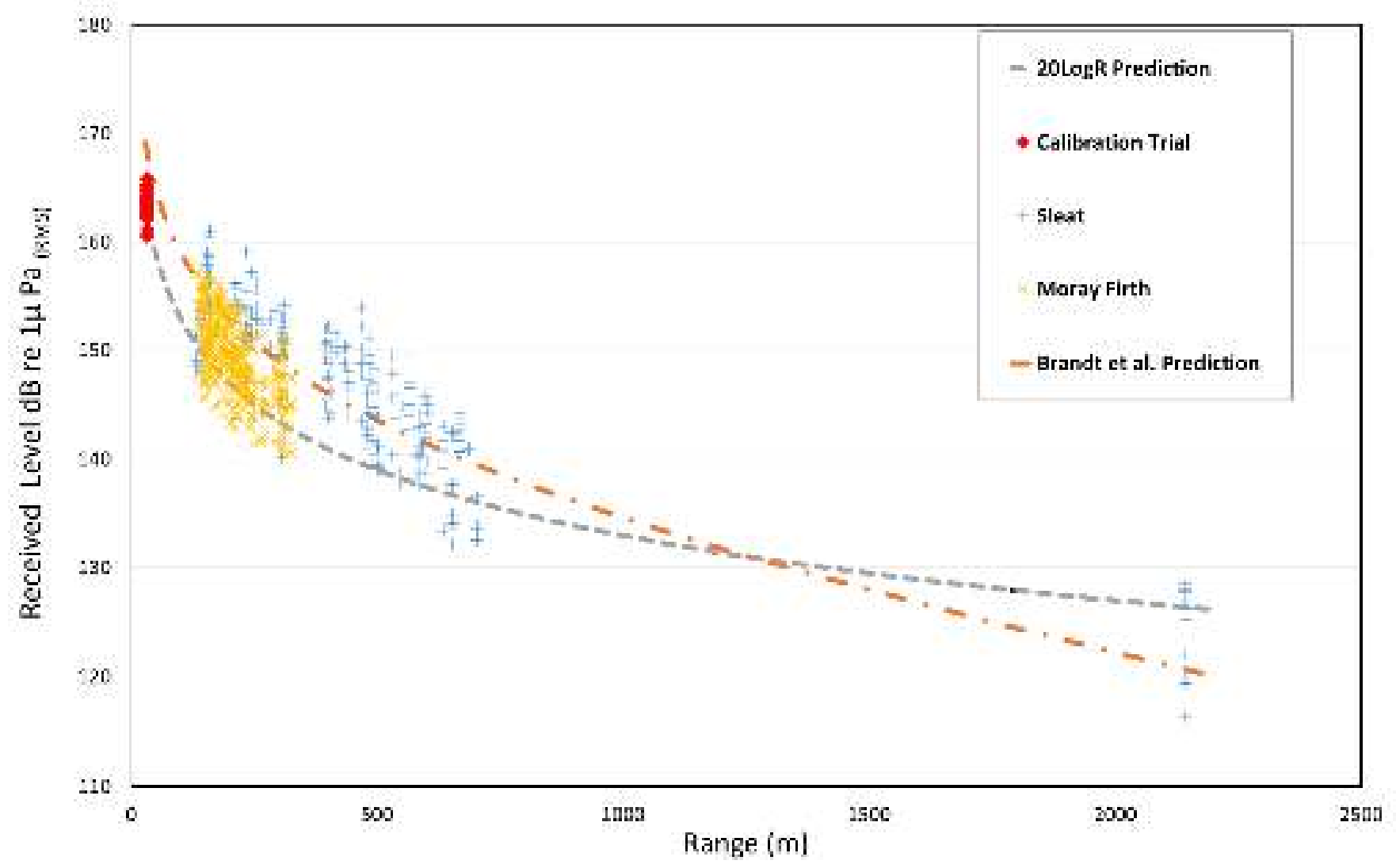

Figure A1. Plots of $\mathbf{7 1 6}$ range vs RMS sound pressure levels measured from a Lofitech ADD in the Moray Firth and the upper Sound of Sleat. Lines show two predictions of received level. One using the equation for sound level with range provided by Brant et al. (2012) and the other based in the source levels measured in this study with propagation loss from spherical spreading plus frequency dependent absorption.

The spar-buoy recorder which was routinely deployed during CEEs to provide a dataset to indicate propagation loss in the study habitat. These were only available over the limited distances over which the boat and buoy drifted apart the course of a CEE. In both 2013 and 2014 dedicated trials to measure received levels over a greater range of distances were attempted at the end of each season to minimise disturbance. On both occasions poor weather and limited time compromised the trials; hence, data at greater ranges are sparse.

To analyse the data, ADD signals were identified in sound files recorded on the buoy and acoustic parameters were calculated using Raven software, as described above. The distance between the buoy and the sound source at the time of each measured blast were calculated by comparing simultaneous GPS locations for the buoy and for the research vessel. There were no consistent differences in received levels for the same ADD transmission between the buoy's shallow and deep hydrophones. Figure A1 is a plot of all measured received levels for Lofitech ADDs made over both years and the received levels and ranges for the calibrated recordings described above distinguished by colour. As explained above, compromised dedicated sound trials explain the relatively sparse data beyond $500 \mathrm{~m}$. Two predictions of received levels are also plotted in Figure A1. The first is the prediction of a simple spherical spreading equation 
$T L=20 \times \log _{10}(R)+(1.8 \times R / 1000)$

The term $1.8 \times \mathrm{R} / 1000$ is a frequency dependent absorption term derived using the Ainslie and McColm (1998)'s method in the tool provided by the National Physics Laboratory http://resource.npl.co.uk/acoustics/techguides/seaabsorption/.

The second is the predicted received levels with range for a Lofitech ADD made by Brandt et al (2012). This assumed a source level of $193 \mathrm{~dB}$ and used a semi-empirical formula for transmission loss in the North Sea derived by (Thiele \& Schellstede, 1980), referenced by Brandt et al., (2012)

$T L=(16.07+0.185 \times F) \times\left(\log _{10}\left(R \times 10^{3}\right)+3\right)+\left((0.174+0.046 F+0.005 F 2) \times R \times 10^{3}\right)$

Where $\mathrm{F}=10 \log (\mathrm{f} / \mathrm{kHz})$

In both of the above equations

TL is transmission loss

$f$ is frequency of the signal

$R$ is range in meters

By inspection, the Brandt et al (2012a) prediction provides a better fit to the data than the simple propagation loss model, though it appears that it may underestimate predicted received levels at greater range.

\section{REFERENCES}

Brandt, M. J., Höschle, C., Diederichs, A., Betke, K., Matuschek, R., Witte, S., \& Nehls, G. (2012a). Effectiveness of a sealscarer in deterring harbour porpoises (Phocoena phocoena) and its application as a mitigation measure during offshore pile driving. Retrieved from Husum, Germany:

Gillespie, D., Gordon, J., McHugh, R., Mclaren, D., Mellinger, D. K., Redmond, P., . . .Deng, X.Y., D. (2008). Pamguard: semiautomated, open source software for real-time acoustic detection and localisation of cetaceans. Proceedings of the Institute of Acoustics, 30(5).

Lepper, P. A., Turner, V. L. G., Goodson, A. D., \& Black, K. D. (2004). Source levels and spectra emitted by three commercial aquaculture anti-predation devices. Paper presented at the Proceedings of Seventh European Conference on Underwater Acoustics, ECUA 2004, Delft, Netherlands.

Thiele, R., \& Schellstede, G. (1980). Standardwerte zur Ausbreitungsdämpfung in der Nordsee. FWGBericht 1980-7, Forschungsanstalt der Bundeswehr für Wasserschall und Geophysik. 